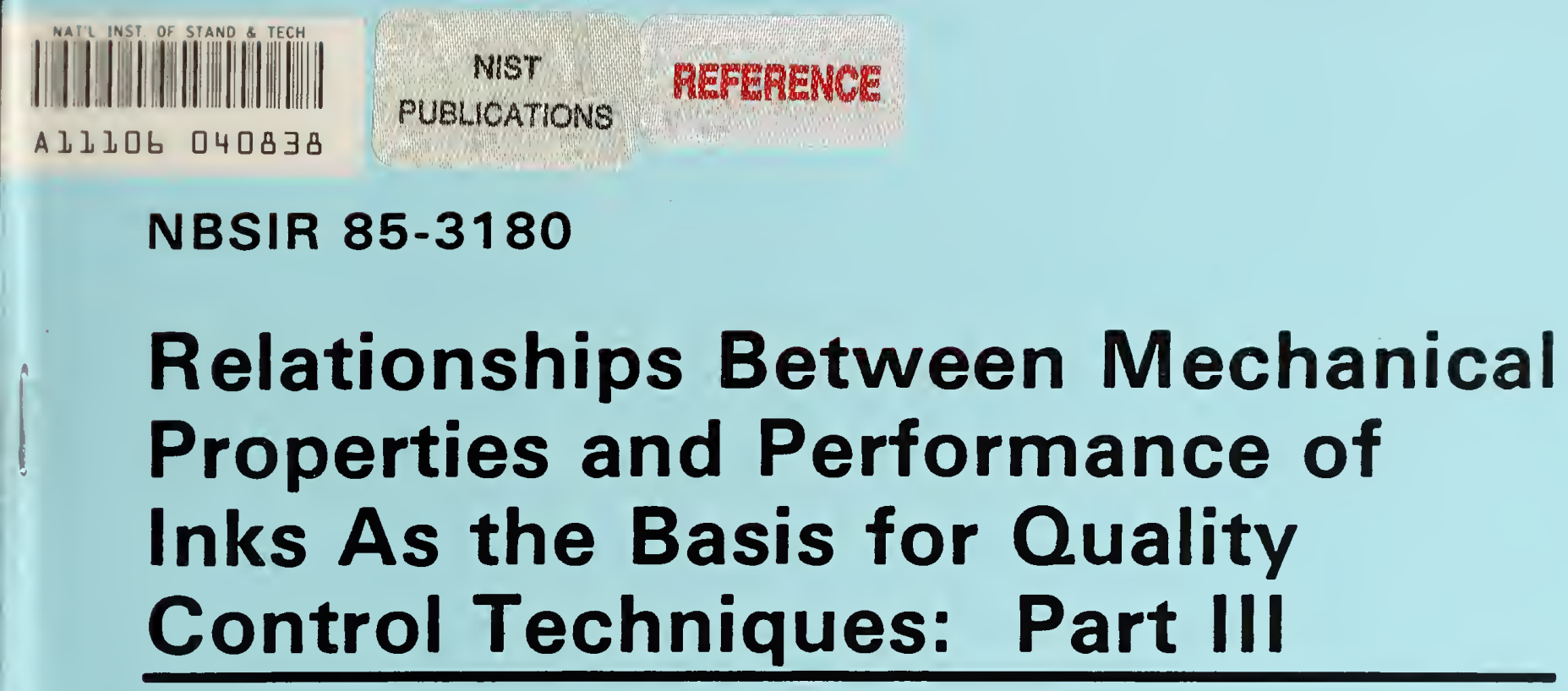

Donald L. Hunston and George W. Bullman

U.S. DEPARTMENT OF COMMERCE

National Bureau of Standards

Polymers Division

Gaithersburg, MD 20899

January 1985

Prepared for

U.S. Department of Treasury

Bureau of Engraving and Printing

partment of Research and Technical Services

ishington, DC 20226 



\section{RELATIONSHIPS BETWEEN MECHANICAL PROPERTIES AND PERFORMANCE OF INKS AS THE BASIS FOR QUALITY CONTROL TECHNIQUES: PART III}

Donald L. Hunston and George W. Bullman

U.S. DEPARTMENT OF COMMERCE National Bureau of Standards Polymers Division

Gaithersburg, MD 20899

January 1985

Prepared for

U.S. Department of Treasury

Bureau of Engraving and Printing

Department of Research and Technical Services

Washington, DC 20226

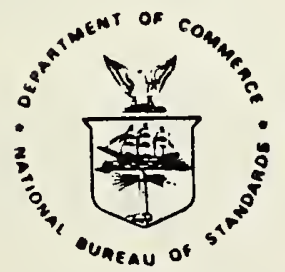

U.S. DEPARTMENT OF COMMERCE, Malcolm Baldrige, Secretary NATIONAL BUREAU OF STANDARDS, Ernest Ambler, Director 



\section{SUMMARY}

This report summarizes the results obtained during 1984 in the joint program between the National Buzeau of $S$ tandasds (NES) and the Bureau of Ergraving and Printing (BEP) to study the mechanical properties of printing inks as the basis for developing quality control tests and procedures. Eight specific research topics will be covered: rubber mill cure axperimeris, ultrasonic tests, poker-chip experiments, squeeze flow tests, a review of black ink test results, recent data obtained for green inks, ink uniformity tests, and results of laboratory ink experiments.

The results from experiments using the rubber mil to study cure suggest that it is the early phases of cure that are most important in performance of the ink on the press. In addition a though the amount of data is very limited, the cure kinetiss messured in the rubber mill experiments appear to be tha same over the range of film thicknesses and temperatures that were examined. These test conditions inciude both those where the cure rates are relatively slow and those designed to more rearly simulate the conditions actualiy present on the press. This is useful because in the latter case the cure rates are too iapid to permit convenient study.

Construction of the BEP ultrasonic cure monitoring apparatus is complete by the addition of the items needed to make tie system self sufficient. Experiments show that this test is sensitive to the effects of temperature and film thickness $2 \pi$

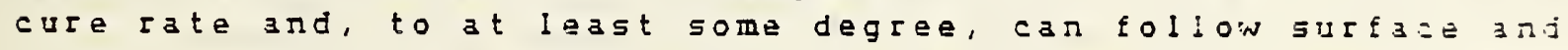
subsurface drying. Both cure rates and induction times were found to change with curing parameters, anc since no simpla relationship between these two properties was found, it was concluded that both must be measured to characterize cura. Without agitation, subsurface drying was found to proceed for days even in thin films.

The poker-chip test results show that the film splitting behavior of the inics. is highly rate dependent. Like viscosity measurements, however, when the film splitting test is used jor cure monitoring, similar results are obtainedover a wide range of low and intermedizte rates. A comparison of the poker-ehip test and viscosity measurements as cure monitoring methods reveals that 3 lthough the former may be more sensitive to initiation, in general, the latter is the preferred method and by itself provides a reasonable characterization of relative ure $r a t a$.

Results for the squeeze flow test suggest that, as a cura monitoring method, it gives data similar to the viscosity tests 
Consequently, the squeeze flow experiment provides a simple alterrative to viscosity measurements for characterizing cure

Tize report reviews the data obtained previousiy for 8 bIack ink samples with known performance on the press. These resuits indicated that inks with siort cure times generally gave poor pertormances while inks with Iong cure times usually periormed well. Inks with intermediate cure times gave a wide variety of performances, and it was concluded that in these cases cther factors, such as the set-up of the press, influenced performance. The inks tested also exhibited a wide variation in cure times. This variation was not anticipated and is suspected to be a majo: contributing factor to the spoilage obtained for these inks. spoilage is defined as the percentage of printed sheets that are unacceptable due to ink related problems.

To examine this hypothesis, 17 batches of green ink were obtained. These inks were examined for cure behavicr and the results showed that there were large batch-to-batch variations even wher corsecutive batches were compared. In general, tie cure times were found to be somewhat slower than those typical of the black inks, and since longer cure times generally mean a sether chance for good press performance, this result may explain why spoilage has been less of 3 problem with the green inks. Nevertheless, the batch-to-batch variations are very large and must therefore be viewed as a problem and probabli a major contributing factor to spoilage. As a result, it was conciuded that the need to identify and control the sources of this vaiation is crucial to reducing ink spoilage levels for both the green and black inks.

To further study these varistions, three production inks were examined by taking samples from the top and bottom of ach batch and measuring the drying behavior. The rasults show that vasiations within a batch contribute significantly to those differences found between batches. For tire three inis examined no consistent trend was found for the variation in drying properties with position in the batch. Although still preIininary, these data suggest that the differences result from a random variable such as poor mixing rather than a iactor such as a systematic segregation of ingredients induced by processing Variatles of this second type might be expected to introduce position dependent variations in properties within a batch.

To determine if controlled and reproducible inks could be fabricated, three ink samples were carefully prepared in the Iaboratory at BEP. When tasted at NBS, these three inks showed very little difference in behavior relative to the variations obseryed in production batches. This sesult is encouraging since it suggestj that systematic studies can be performed with laboratory inks to analyze the effects of variations in formulation and processing on the drying properties. This offers the best hope for identifying the sources of the variations in ink properties and from this identification developing methods and procedures to minimize this unwanted variability. 
요 LA TI ON SH IPS BETWE EN ME OH AN IC AL PROP ERTI ES AND PER EORM AN CE OE IN KS AS IHE BAS IS EOR QUALITI CONTROL TECHNIQUES

In cooperation with the Bureau of Engraving and Printing (BEP), NBS is studying the rheological properties of grinting inks, particularly properties associated with drying behavior, in an effort to develop a better basic understanding of the factors that control. ink performance. The goals in this work are to use the information developed to generate test methods and guidelines for improved ink quality control. In addition the results will be valuable in formulating improved inks. This report describes the work performed during 1934. It covers progress.in eight research areas: (1) the use of a rubber mill as an ink cura device, (2) the further development of the ultrasonics test device, (3) the evaluation of the poker-chip test as a method to monitor ink curing, (4) the continued development of the squeez flow experiments as a method to study ink curing, (5) a ravi ew and evaluation of results previously obtained for black inks with known performance, (6) an analysis of Iesults obtained for l? rew samples of green ink, (7) an examination of ink batch uniformity with production lots, and ( 8 ) $3 \pi$ evalustion of reproducibility for ink samples prepared in the laboratory. Each of these topics will be discussed in detail below.

RU BE ER -MILL ERPER IMENTS: As discussed in the previsus Annual Report ( 1 ), the rubber mill provides an acellent and 
versatile device for curing inks under circumstances that simulate some of the conditions present on the printing prass The advantages of the rubber mill as compared to other roller deyices are that both rolis are heated for more uniform temperature control and the film thickness can je variad in a control led manner.

By using the rubbermili, there are two important guestions related to the study of ink curing behavior that canbe addressed: (1) what part of the cureis most importantirink performance on the press, and ( 2 ) are the kinetics messured the mill studies the same as those operating on the press

Although complete and definitive answers to thes? questions would requife 3 lorg and detziled study of kinetics, the tests performed here provide some valuable insight into thase questions.

A series of experiments was condugted on 3 sample of biack ink using different cure temperatures and film thicknesses. The times requized for solidification were reasured and the Eesults are listed in Tabie I. Soliditication was defined as the point where the ink was completely dry and no flow could be obtained. This point could easily be estimated by noting that all of the inle transferred to the back roll on the mill when dry. Eased on the data from these tests, an estimate could be made for the corresponding time to solidification under press conditions, i. e. preheated ink, $100 \mu \mathrm{m}$ thickness, and $80 \mathrm{C}$. Such an estimate indicates the ink-would completely harden in significantiy less than l minute. The actual residence time oi the ink on the press roliers is much less that 1 minute. Fis 
suggests that it is the eariy stages of the drying that are most important :or proper press performance. of course, tre Iater phsses of cure razy be of concera for other asgects of spoilige, suah as the smearing and sticking together oi printed sheets. Nevertheless, in light of the apparent importance of the 3 ily phases of cure on press performanee, zuture work will focus ch this aspect.

A second interesting and important result was 3 lso obtained from these cure data. When the logarithm oi the time to solidification was plotted against reciprocal temperature, the points were found to fall roughly along parallel straight lines for each thiskness (Eigure 1). Obviously, the data are linited and the uncertainties in the time to solidification measurement are significant so orly 3 first impressions can be obtained. Nevertheless, within these limits, there is no indication of a major change in kinetics over the Iange of conditions studied More experimerts are planged but, for tire morent at lasst, it appears that the standard test conditions used intiis work (oj and 0.3 mm film thickness) should provide a good indication ot the relative reaction rates on the press

ULTR AS QNIC E⿱丷三ERIMENTS: The details of the ultisonictest apparatus being developed for BEP (see Figure 2 ) have been described previously (1,2). Since lastyezr's Angul Repor: t: severai additional components have been added to make the apparatus 3 stand-alone system: an oscilloscope, a recorder and an attenuator. A prototype temperature control chamber has bean 
completed and tests to evaluate this preliminary design are now underway. The results of the first experiments, which evaluated temperature and film thickaess effects, will be reported here.

Eigure 3 shows the drying curves obtained ty measuring the increase in attenuation as a iunction of time in the ultrasoric apparatus as differant film thickness samples of tine same ink cure at $60 \mathrm{C}$. These curves indicate that both the cure rate and the induction time changad as the film thickness was decreased 3: though the major change was in the cure rate. A five fold reduction in the thickness increased the drying rate $\log$ roughy 25 fold while decreasing the induction time by only zbout $20 \%$. The effects of increasing temperature at a fixed film thickness $(0.007 \mathrm{~cm})$ showed similar trends, Eigure 4 . The differences in rates observed here, however, were less than those seen in Figure 3. Nevertheless, an increase in cure temperature of 20 C still produced roughly 3 fold increase in rate. The induction period also seemed to decrease as the temperature ins increzsed although the particular curve shown hese for 40.7 C does $n \in t$ show this trend.

Many of the curves obtained in these experiments exhisited 3 distinct hump (see Figure 4). This hump is believed to be $3 \pi$ indication that there were two drying processes: surface drying and subsurface drying. The general observation was that when the hump was reached, the surface was dry but the ink below the purface was not (even in thin films). Thus, the ultrasonic technique shows promise 35 a measurement tool for both suriace and subsurface drying, and the Iatter is difficult to monitor by other techriques. The measurements indicated that the subsurace 
drying is very slow and continued for days. This could be an ¿rportant problem if the ink thickness in printing were to je too la $5 \mathrm{ge}$.

The Iesults shown in Figures 3 and 4 also cieariy demonstrate that both the induction times and cure rates changed significantiy as a function of temperature $3 \pi d$ íin thickress No simple corfelation between the two properties was observed in these tests, however, and thus a major resultof tiis study is that both must be measured to characterize the ink auring. II only one is messured, the reliability of the test as a quality control tool will be severely limited. The Eigures also suggest that without 3 gitation the drying rates are gery low. Conditions which produced complete drying on the rubber mill in 40 min. measurable changes associated with diying in the ultiasonic apparatus for days. Additional experiments to investigate this difference are planged.

PQKER-OHID IEST: The pokeI-chip test (EIguIe S) has also been described in the previous Anguai Reports (1,2). With the completion of the computerization of the NBS tensile tesi machine, it was possible to examine the poker-chip test over a very wide range of film splitting rates (cross-head speeds) as shown in Eigure 6. As pointed out in the previous Iy (1, 2), :he Iesults show that, like viscosity, the failute ioadstortilic splitting are a strong function of tate. This is an Important Iesult and Iaises questions with regard to what Iate should be usedin cure monitoring tests. To study this question, a 
particular ink sample (batch 9 prepared on $1 / 16 / 82$ in the BEP guality control program) was cured on the rubber mill, and periodicaly during the cure, samples were'removed and characterized inith the poker-chip test. The NBS test devtcemaje it possible to examine the partially cured inks over a wide rangi of rates. The results, which. were first presented in last years Anתuzl Report (1), are shown in Figure 6. When these results are compared to cure data curves obtained praviously $(1,2)$ for other inks using viscosity experiments (Figure 7), two important similarities (in addition to the high rate defendence) are observed. Eirst, over most of the range of rates examined, curing produces a roughiy vertical shift in the curves odtained with soth techniques. Second in both measurements there is $z$ tendency. for the curves to come together at high rates. This means that in using either test to monitor cure, there area variety of intermediate or low rates where the choice of a testing rate wil! have Iittle effect on the results.

since both the poker-chip and viscosity tests have now been developed into potential curemonitoring tools, it is of interest to compare them. The first such comparison was presented in last year's report ( 1 ). Since then a number of additional experinents of this type have beer conducted. In these experiments samples of various inks were cured to various degrees on the rubber mill 3nd characterized with the two tests. The viscosities were meziured at a shear rate of $5 \mathrm{sec}^{-1}$, and the poker-chip tests were conducted at a cross-head speed of $0.0008 \mathrm{~cm} / s e \mathrm{~s}$. The Iesulting data were then compared, and 3 typical plot is shown in Eigure 8. The vertical scale in this Figure represents the 
viscosity in mPa sec divided by $10^{6}$ sor the shear Elow tejta and the failuze load in kg for film splitting tests. Suciplots reveal a ciear similarity between the two experiments. Fine poker-chip results are perhaps more sensitive to the onset of cure. Once cure is well underway, however, the poker-cilp test Loses accuracy in that it shows a good deal of scatter and, on average, Iittle change with curing. Inthis range the film tendj to split rather cleanly and exhibits a grainy structure. Tia viscosity test on the other hand gives a claar indiation of curing over most of the drying range. This indicates that tie viscosity test is a more complete, overall cura ressuring $p=0$ cedure.

Data such 35 that shown in Figure 8 are now availabie for a number of different ink samples and the trends are quite consistent. Based on this data base, it is now felt that athough the poker-chip test provides some additional insight into curing, thisinformation is not sufíiciently valus quality contro: point of view to make it worthwile to utilize both a viscosity type test ard the poker-ship test wien characterizing the curing of an ink. To state this another way, the results show that for the ink formulations tested here viscosity test will probably detect any ink cure probiens that show up in the poker-chip test. Consequently, future experinen:s will focus on the viscosity test or 3 suitabla sujstitute evaluation procedure.

SQUEEZE ELOW TESE: As mentioned previsusiy (t), tie squee =e 
flow test is being considered 353 quick and easy experiment that an be used in place of the more complex and time consuring viscosity measurement method to follotv cure. This test is conducted by placing an ink sample between two plates and applying a compressive load to the top plate (Eigura 9). The plate separation then decreases as a function of time with the major change occuring in less than 30 seconds. As a zesult a relatively reproducible measurement can be obtained after 60 seconds. Although this experiment is much simpler to perform thas a careful shear viscosity test, the flow involved is more comples. On the other hand, shesr viscosityplays an iafortant ro!e in the squeeze flow test, and the technique has the advantage that it car be performed quickly and asily with inespensive, off-the-shelf equipment. For the experiments performed here, a simple hardness tester was used, and thus the results are expressed in terms of hardress rumbers; higher hardness numbers mean a larger plate separation at 60 seconds or a higher viscosity.

Since the flow pattern in the squeeze flow test is not well defined for a complex, nonlinear viscoelastic fluid such as the inks, it is useful to conduct a detailed comparison between the result of this test and those for a well defined shear flow viscosity test. This will help determine if the results for the squeeze flow tests can be interpreted in a maner equivalent to the results of the viscosity tests. Such experiments 3 re now underway. Meanwhile, a series of tests was performed using the squeeze flow experiments to follow the cure behavior of 3 wide range of black and green inks. The results of these tests will 
be reported in detail below, but it is worth noting here that the data from these experimerts clearly demorstrate tre ability of

this test to easily monitor cure behavior in inks. Moreover, the general shape of the cure curves obtained by squetze fiow mẹasurements is remarkably similar to that for the curves obtained by viscosity tests. Consequently, the results 3 i vary encouraging with regard to the possibility of substituting squeeze flow messurements for. viscosity tests.

REVIEU OE REEULIE EOR BEER'S QC INKS: Before discussing the new results for tests conducted with the 17 batches of green inks, it is useful to review ore set of experiments presented and discussed in last year's Anrual Report (1). These experinents involved the evaluation of a specially selected set of black inks. During a period of 4 weeks in early 1982 , samples were taken from every batch of black ink formulated at BEF and theje sarptes were stored in freezers. For all of these inks detil:ad spoilage figures were obtained at BEP by tracking tia pinging performance of each batch. Based on these figures, eight inis were selected for further study: four with very low sporiage (Iess than 1.7\%) and four with very high spoilage (greateztian 9. $8 \%$ ) The stored s3mples of these selected inks were tien retrieved and subjected to detailed characterization eaperiments Although variations in 3 number of properties were found, the oriy parameter that correlated with spoilage was the cure behavior. The drying airves for the eight inks were measured by curing on the rubber mill and monitoring changes in properties 
with the squeeze flow test. The results are showr ir Eigure io. Solid curves are drawr through the poirts for the low 3 pol $13 \mathrm{ge}$ inks while dashed lines are used for the high spoilage inks.

Each ink curve is designated by a letter, and Table II lists the Eatch numbers and fabrication dates.(in 1982) for these inks Table I also Iists the spoilage figures ard the cure rates determination (Fast or SIOW) made in tests at BEP Using iR experiments.

Based or anexamiration of these results, last years Anתual Report ( 1 ) concluded that the cure rates could be divided into ths Iegions: East, irtermediate, and slow. The irks Nith ids cure rates inevitably gave poor performarce, those with slow cure Iates almost always gave good performance, and those with intermediate cure rates could have a wide range of periormarce levels. The eviderce suggests that ir this third case, the performance depended or other factors in additior to the isk quality, for example, the set-up of the press. ore simpleway to compare cure rates is to determine the time required for the squeeze flow test results to raach 3 hardress number oi 30.

UnIike the previously used time-to-solidification measuremert, this procedure has the advartage that the tire car be determined quite accurately since both the times to lower hardress and the times to higher hardress can be used for interpolation.

Moreover, Iike the previous method, this techrique includes the influence of both the induction time ard the cure rate. these reasors, it was concluded in the previous Arrual Report (1) that this evaluation method represents a good choice for characterizing the inks wher only a single parameter is to je 
used.

Tabie II lists the values of this parametar for the eight inks tested. By using these results, tine previous work ( 1 ) suggested that inks with time to 30 inadness values less than 32 min. had a cire 5 ate tinat was too fast and hence these inks gave poor press performances; inks with values greater than 33 iaj sufficiently slow cure rates to give good performances; and inks which had intermediate values of this parameter involved the risk of unsatisfactory performance. Although these conditions included all of tine test rasults obtained, it is reasonable to assume that there must also be a lower limit to the acceptable range of cure rates, i.e., cure times that are beyond zome Iimiting value will indicate cure rates too slow to give adequate performance or the press. The results to date in this program, however, suggest that this end of the scale is gererally not the majoI problem.

Since these results inere reported in last yesr's Angus! Report (1), ore new observation has been made; i.e., the degree of batch-to-batch variation that was found in tinese testz was surprisingly large. The cure times (time to 30 hardness) variad by almost a factor of 2. This seems disturbingly high and is clearly undesirable although it must be admitted that these inks represent extremes over a 4 week period. The inks undoubtedly involve different lots of starting materials, different peop!e performing the formulation, and possibly veriations in storage times and histories. As a result, it is difficult to determine how typical these variations $35 \mathrm{e}$. In the new experinents 
conducted recently with the green inks, these potential complications were considered in designing the test plan.

RESULIS FOR NEW INK SAMPLES: The recent studies employed a series of 17 butches of grean ink. All of the samples were taken in a 4 day period ard in many cases involved samples from consecutive batches made by the same people with the same starting materials. The samples were, storedin a freezer for orly a minimal time period before testing. The tests involved characterizing the cure zate using the rubber mill-squeeze flow procedure. The results are shown in Figures 11 to 14 where esch Figure contains data for batches formulatedor a giver day.

Table III I ists the formulation date (in 1983), batch numbe, and correspording symbol used to represent the results in the Figures.

Despite the fact that most of the uncertainties involved in the tests on the black inks were controlled in these recent experimerts, the batch-to-batch variations in the greer inks eontinued to be very large. Here again, the cure times difiered by almost a factor of 2 ; and in some cases, these large differences were seen in consecutive batches made of the same day. Moreover, these variations were not isolated to a single day but were typical of the results obtainedall 4 days. This same trend can be seen in Table II which Iists the time to 30 hardress values for the 17 batches of greer ink.

Although the spoilage figure for these inks were not available, it is instructive to compare their characteristic times to cure with those obtained previously for the black inks 
This is done in Figure 15 with dashed lines separating the iast, intermediate, and slow cure regimes. Interestingly enough, all but one of the green inks feli into the slow cure region wirere good press performance was normaliy obtained for the black inks. The single green ink batch faling outside this range had an intermedizte cure rate which could well give good performance i other factors are properiy controlied. The data here is obviously limited but they do suggest that the green ink formulation shows large batch-to-batch variations just as was found for the black inks. For the green inks, however, the cuze rates were, on average, significantiy slower that those for the black inks and this may expiain why the spoilage ifigure for the green inks have generaliy been lower than those for the black inks.

The final and most important conclusion from the test conducted here concerns the possible consequences of the batchto-batch variations. Previous work has concludad that the press and other factors can-be adjusted to compensate for a wide range of ink parameters so long as the variations in theseparameters occur slowly over a time period of months or years. Rapid and unpredictabla variations such as those seen in Eigures 10-14, however, represent a serious problem that canclearly lead to spoilage if not properiy controlied. At the present time, there is no explanation for these variations, nor any reason to suspec: that they must be present. As a result, there is a need to develop an understanding of the factors that are responsible tor these batch-to-bitch differences. 
UN IF ORMI TY OE ERODUCII GN INKE: In wiew of the above results, there zie two important questions that must be addressed. First, to what extent are the apparent batch-to-jateh variations really reflections of non-uniformity withineach batch. The degree to which this is true will have a great influence on what must be done to minimize such variations. The second question concerns the ability to prepare laboratory ink batches with minimal variations both within and between batches. Only if well-controlled, reproducible laboratory samples can be fabricated will it be possible to study the origins of the variations in properties for production ink batches in 3 sinple and systematic way. In an effort to address both of these questions, ink samples were obtained from BEP and tested at NBS. To judge the homogeneity of ink batches, tests were conducted with samples from three different production batches In each case two samples were obtained: one from the top of the batch and the other from the bottom. The drying behavior cf ezah sample was then measured using the rubber mill-squeeze flow tes:. The results are shown in Figure 16. A different symbol is used to designate each batch with the open symbols indicating the samples from the top of each batch and the filled symbols ior the samples from the bottom.

The results in this Figure represent only three jatches and thus the conclusions must be taken as tentative; nevertheless, thrae important observations can be inade. First, very Eignificant variations in cure behavior were found to occur within two of the three batches. To compare these within batch 
differences with the variations measured previcusly between batches, the curing behavior of these samples was characterized by determining the time to 30 hardness yaiues. These rasults were then plotted in Figure 17 together with the results trom Figure 15. Clearly the within-batch heterogereity represents a significant fastor contributing to the batch-to-batch variations Consequently, correlations between the spoilage figures for various batches of ink and their performances can only be established when the differences are lagge enough to overcome tine influence of the within-batch variations.

The second observation that can be madefrom the data in Figure 16 concerns the shape of the drying curves. Here again the limited rumber of results must be noted but for these cases at least it appears that samples from the same ink batch give drying curves with similar shapes but different induction times. This is in contrast to curves for samples from different bitcies where both the shape and induction times can be different. Titij would suggest that the batch-to-batch variations -may in some cases be qualitatively different than the within batch heterogeneity.

A third important observation can also be made from the drying curyes. It is of interest to see if the inhomogereity within a batch exhibits any systematic trends. The existence or absence of such trends provides an important clue as to the source of the variztions Ar examinztion of the results in Figure lo clearly shows that, for these samples at least, ro consistent trends are present; i.e., in one case the sarple t:om 
the top of the batch gave a shorter cure time while in another case the reverje was true. It might be speculated, therefore, that the variations within a batch are rancon inhomogeneities attibutable to factors such as inadequate mixing rather than some type of segregation of ingredients produced by the processing itself. The latter circumstance might be expected to produce the same effect each time thus leading to a consistent trend and property variations that depend on location in the batch. Additional studies are needed to test this speculation, but these results provide a very useful indication with regard to what future experiments should be conducted.

VARI ABILITY IESTS CN LA BORATORY INKS: In view of the Iarge yariations in ink properties, it is important to determine if laboratory samples can be produced with controlled and reproducible properties. To examine this question, three ink batches were fabricated in the laboratory at Bep using starting materials from the same lots and taking care to minimize yaiations in thé processing. These samples were tested at Nís for drying behavior again using the rubber mill-squeeze flow technique. The drying curves are shown in Figure 18. These results can be compared with the data for production inks shown in Eigure 16. From this comparison it is clear that the laboratory samples were very similar relative to the production inks.

This same observation can be made in another wayky again using the time to 30 hardress values as characterization parameters for cure. These times were determined and tine results 
plotted together with the data from Eigure 17 in Eigure 19 . This graph shows that controlled and reproducible inks can be made in the Iaboratory.

Although these experiments involved only one set of

baboratory inks, the results are very encouraging because they suggest that systematic studies car be performed with latoratory inks to analyze the effects of valiations in formulations and procissing on the drying properties. This offers the best hope for identifying the sources of the variations in ink propertiss and, from this identification, developing methods and processes to minimize the variability. 


\section{RE FE RE NC ES}

1. Dorald L. Hunston and George W. BuIlnar, "Relationsip

Between Mecharical Properties and Performanee of inks as the. Basis for Quality Cortrol Techriques: PaIt II," NBSIR 842901, November 1984.

2. Dorald L. Hurstor, "Relationships Between Mechanical Properties and Performance of Inks as a Basis for Quality Control Techriques," NBSIR 83-2691, May 1983. 
EA BLE I: CURING OF INKS OE RUBBER MILL

\begin{tabular}{ccc}
\hline $\begin{array}{c}\text { TEMPERATURE } \\
(C)\end{array}$ & FILM THICKNESS \\
$(\mathrm{mm})$ & $\begin{array}{c}\text { TIME TO } \\
\text { SOIDIEICATION } \\
(\mathrm{mI})\end{array}$ \\
\hline 40 & 0.3 & 65 \\
40 & $\sim 0.1$ & 26 \\
50 & 0.3 & 31 \\
50 & $\sim 0.1$ & 15 \\
60 & 0.3 & 21. \\
60 & $\sim 0.1$ & 9 \\
70 & 0.3 & 12 \\
70 & -0.1 & 5 \\
\hline 0 & 0.3 & 8 \\
\hline
\end{tabular}


IABLE II: COMPARISON OF INX CURE REEULTS

\begin{tabular}{|c|c|c|c|c|c|}
\hline $\begin{array}{c}\text { INK } \\
\text { BATCH }\end{array}$ & DATE & DESIGNATION & $\begin{array}{c}\text { SPOILACE } \\
(\%)\end{array}$ & $\begin{array}{l}\text { TIME TO } 30 \\
\text { HARDNESS } \\
\text { (III) }\end{array}$ & $\begin{array}{c}\text { EEP } \\
\text { CURE RATE }\end{array}$ \\
\hline 9 & $1-16-82$ & A & 22.8 & 37 & $S=\subseteq[O W$ \\
\hline 10 & $1-22-82$ & B & 11.2 & 31 & $E=F A S T$ \\
\hline 3 & $1-26-82$ & C & 9.9 & 29 & $E$ \\
\hline 17 & $1-28-82$ & $D$ & 13.5 & 27 & $\mathbf{E}$ \\
\hline 7 & $1-12-82$ & $E$ & 0.74 & 33 & $s$ \\
\hline 5 & $1-25-82$ & $E$ & 1.64 & 42 & 5 \\
\hline 13 & $1-27-82$ & C & 1.19 & 41 & $s$ \\
\hline 9 & $2-2-82$ & $H$ & 0.95 & 52 & $\mathbf{s}$ \\
\hline
\end{tabular}


TABLE III: CURE DATA FOR GREEN INKS

\begin{tabular}{|c|c|c|c|c|c|}
\hline BATCH & SYMBOL & IIME TO 30 & HA RDNESS (min) & EOR I NKS & EA $3 R I C A T E D O N$ \\
\hline NUMBER & & $11-14-83$ & $11-15-83$ & $11-17-83$ & $1 \pm-18-83$ \\
\hline 1 & $\square$ & 49 & -- & 62 & 44 \\
\hline 2 & + & 54 & -- & 39 & $5 i$ \\
\hline 3 & $\Delta$ & 55 & -- & 58 & $3 E$ \\
\hline 4 & $\vartheta$ & 60 & -- & 55 & 54 \\
\hline 5 & $x$ & 52 & -- & -- & -- \\
\hline 6 & $\Delta$ & 50 & -- & -- & -- \\
\hline 14 & 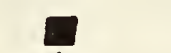 & -- & -- & -- & 50 \\
\hline 15 & 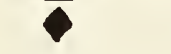 & -- & 45 & -- & -- \\
\hline 16 & - & -- & 51 & -- & -- \\
\hline
\end{tabular}




\section{EIGURE CAPTI QNS}

Eigure 1: Arghenius type piot of time to solidification data at two difierent film thicknesses: $\square=0.3 \mathrm{~mm}, \Delta=$

0.1 mm. The lines correspond to activation energies of 3 bout $12 \mathrm{kcal} / \mathrm{mol}$.

Figure 2: Diagram of the ultrasonic test apparatus with typicai oscilloscope display (test irequency is 3 or $5 \mathrm{MHz}$ ).

Eiguze 3: Drying curves from ultrasonic apparatus at three íim

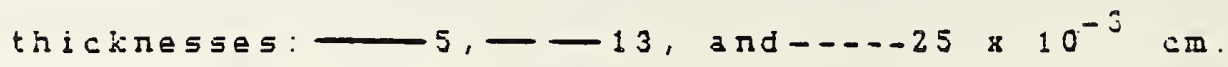

Eigure 4: Drying curves from ultrasonic apparatus for film of thickness 7 × $10^{-3}$ am at three temperatures:- 10.7 , $-50.8,3 \pi d-\infty-\infty 60.4 \mathrm{C}$.

Eigure $\underline{\text { i }}$ : Diagram of poker-chip test and sample of data output. Eigure 6: EiIm spIitting force measured at various fates tor smples of ink batch $9(1 / 16 / 82)$ cured on mill tor times of: $0 \mathrm{~min} \odot, 7 \mathrm{~min} \square, 15 \mathrm{~min}+, 25 \mathrm{~min} \Delta$, $32 \mathrm{~min} . \%, 37 \mathrm{~min}, \bigcirc$, and $43 \mathrm{~min}$

Ei gure 7: Viscosity as a function of shear rate for sampies of ink $8 K-60$ cused on mili for 0 min. $x, 10$ min. $20 \mathrm{~min} . \square$, and $30 \mathrm{~min}+$

Eiqure g: Compzrison of poker-chif, data or same ink: batch $17(1 / 28 / 82)$. Vertical jars or poker-chip data represent scatter ranga found with 8 tests.

Eigure 9: Disgram of squeeze flow test and schematic of data ior urcured-, and partially cured---ink. 
Ei gire 10: Squeeze flow results for 3 specially selected black inks cured on tine rubber-mill. Dashed curves correspond to inks with high spoilage while solid curves are for low spoilage inks. Letters designating particular ink samples are defined in Table Ii

Ei gure 11: Sque ze flow results for green inis fabricatad or $11 / 14 / 33$ and cured on the rubber-mill. The symbols used in this graph dasignate the batch number and $35 E$ defined in Table III.

Eㅁㅁ들 12: Squeeze flow results for green irks fabricated on $11 / 15 / 83$ and cured on the rubber-mill. The symols used in this graph designate the batch number ard are defined in Table III.

Eigure 13: Squeeze flow results for green inks fabricated on $11 / 17 / 83$ and cured on the rubber-mili. The symbols used in this graph designate the batch number and are dezined in Table III.

Eigure 14: Squeeze flow results for green inks fabricated on $11 / 18 / 83$ and cured on the rubber-mill. The symolis used in this graph designate the batch number ind a $=$ defined in Table III.

Fi quze 15: Comparison of ink cure times for ink sampies including data from Eigures 10 to $14, \triangle$. Data tor the Black inks, $\square$, comes from Tabie II, ant tasel 0 . the bIack ink results, vertical dashed lines are drawn to separate the data into performance reglon according to press behavior. 
Figure 16: Drying curves for production samples of BK-62-ficA

Mod. 3A inks made on 7/9/84: Sample number 5 - D, 6 $\square, 9-\Delta, 10-\Delta, 11-0$, and $12-0$. Open symbols indicate samples from the top of the batch; filled symbol from the bottom.

Fi qure 17: Time to 30 hardness yalues for 3 pariety oi black and green inks. Data from Figure 16 is plotted at the top of the graph using the same symols 35 in Eigure 16. The other points are taken from Eigure 15.

Eigure is: Drying curves for laboratory samples of eK-oz-aCA inks fabricated on 6/30/84: Sample number $1-\square, 2$ $\Delta$, and $3-\Delta$.

Eigure 10: Data for laboratory inks added to Figure 17 i same symbols as Figure 18 . 
Figure 1

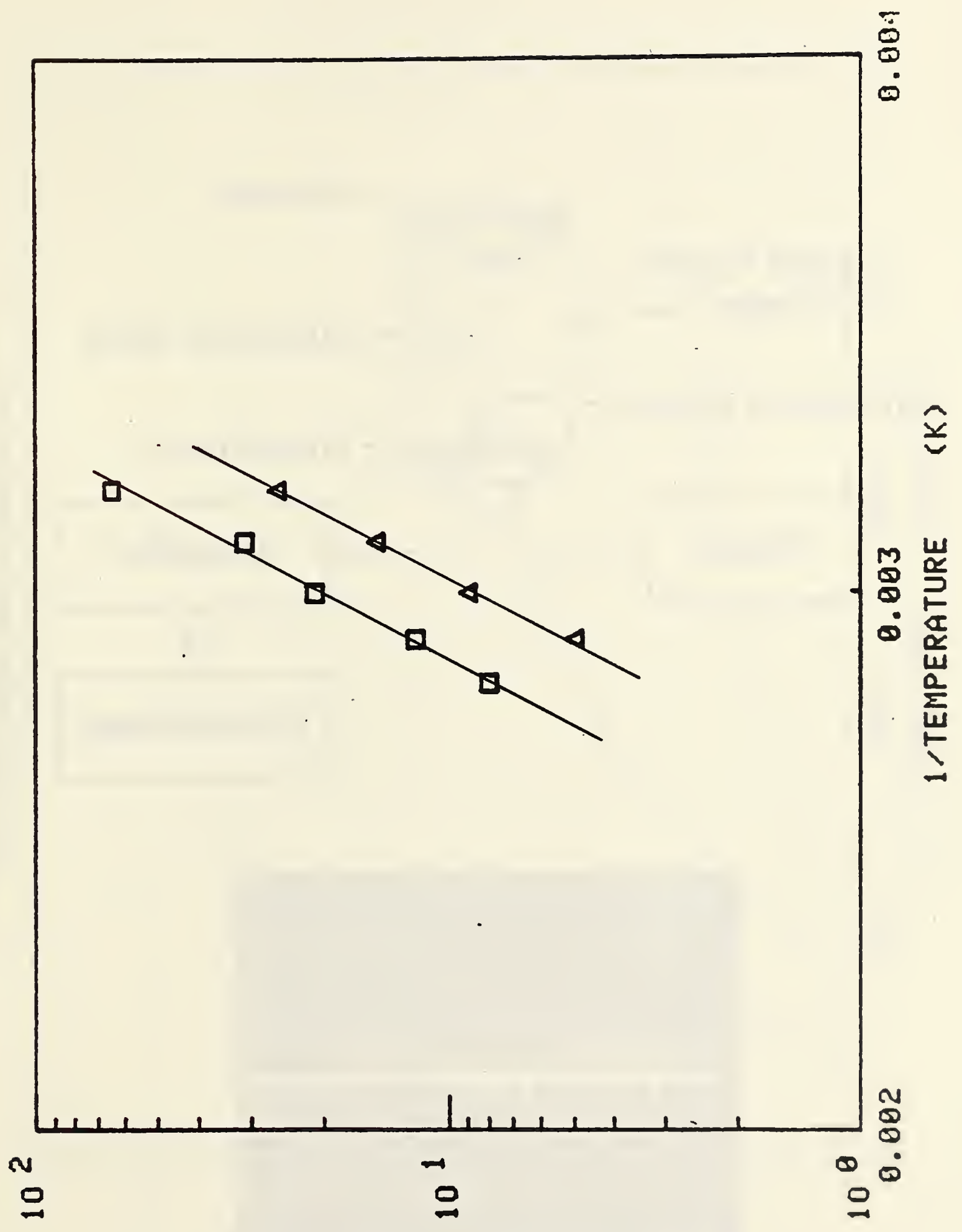

mआEய 
Figure 2
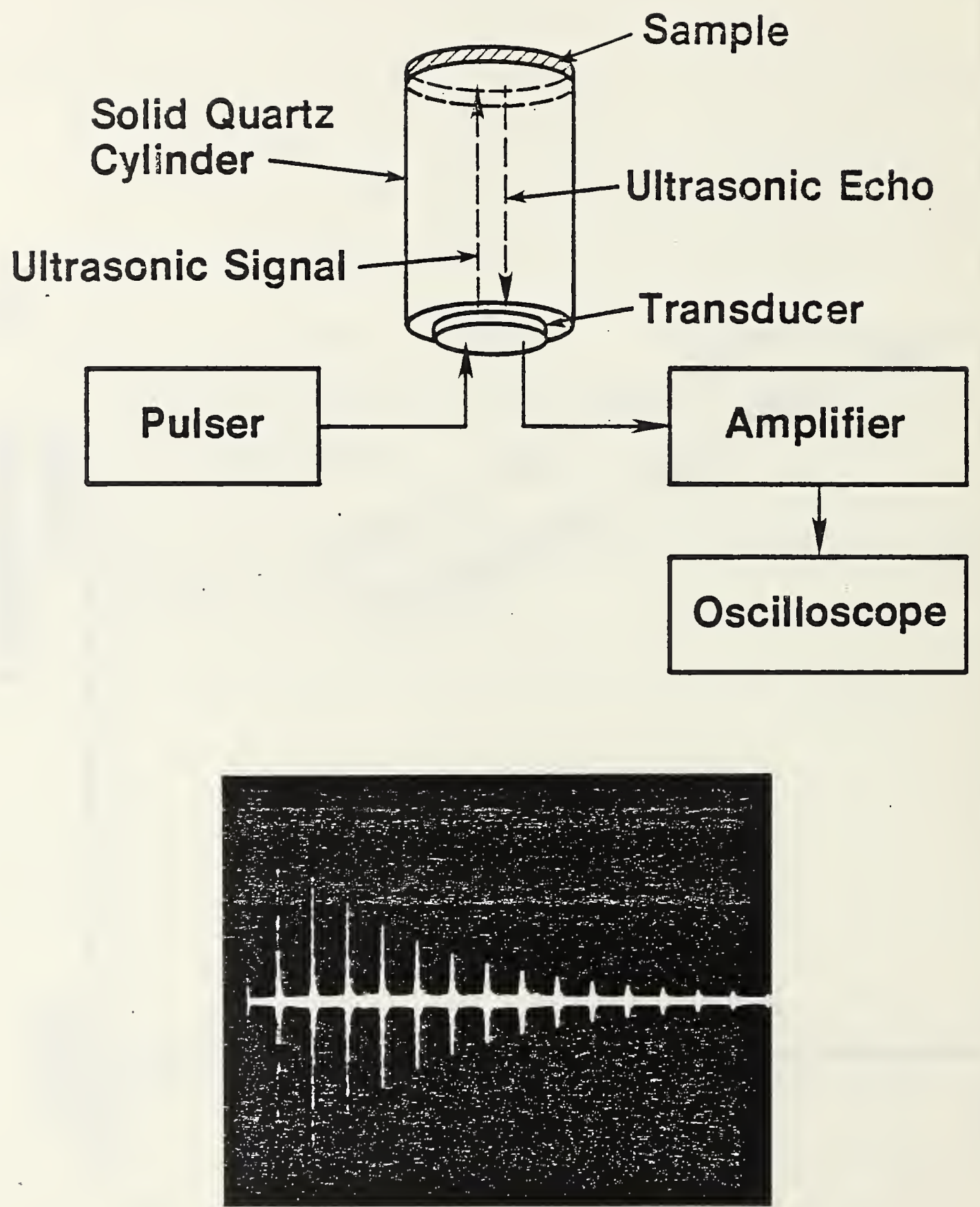
Figure 3

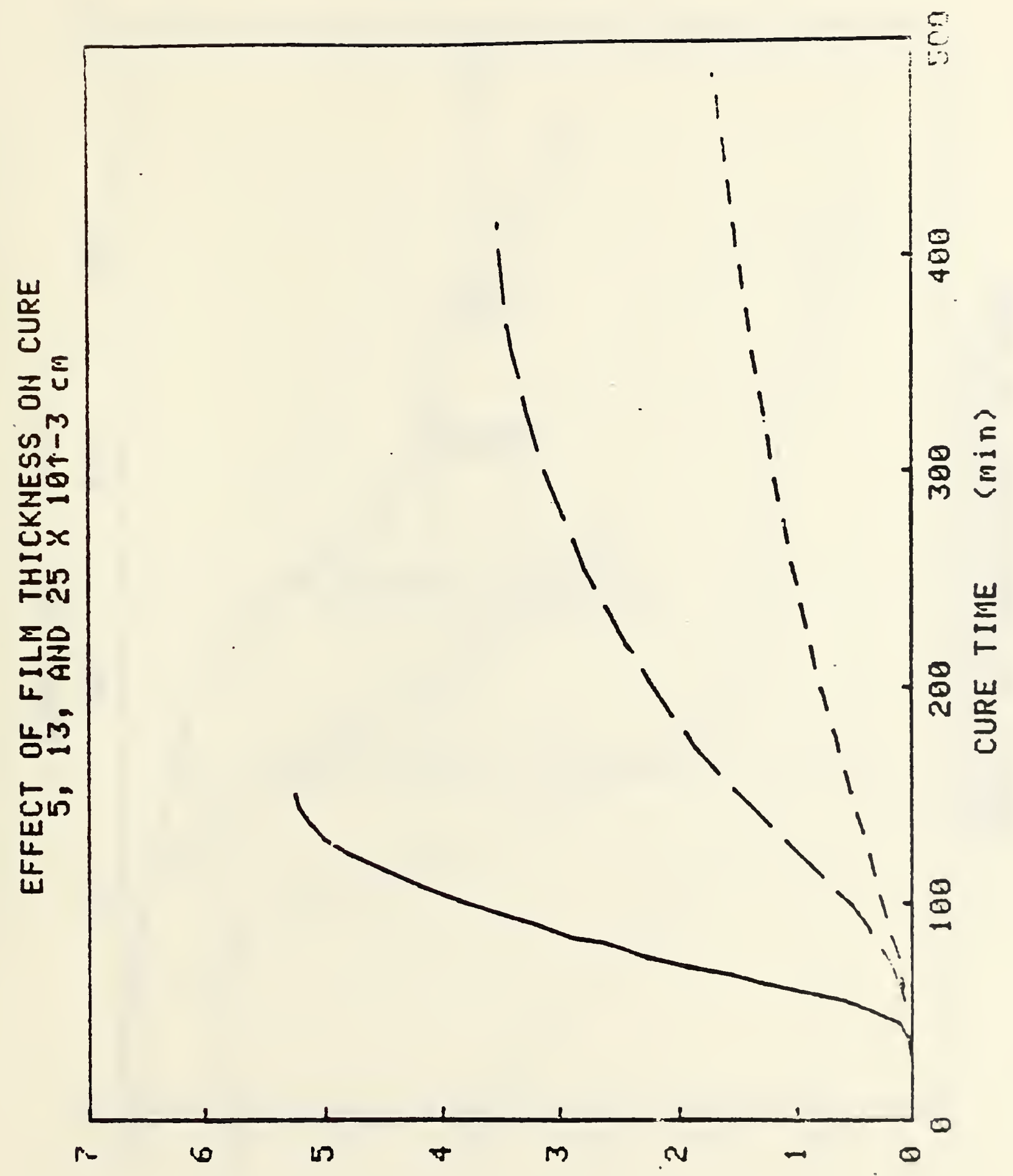

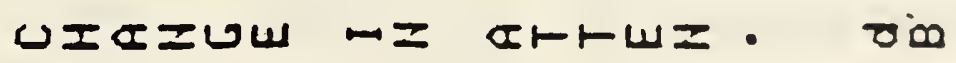


Figure 4

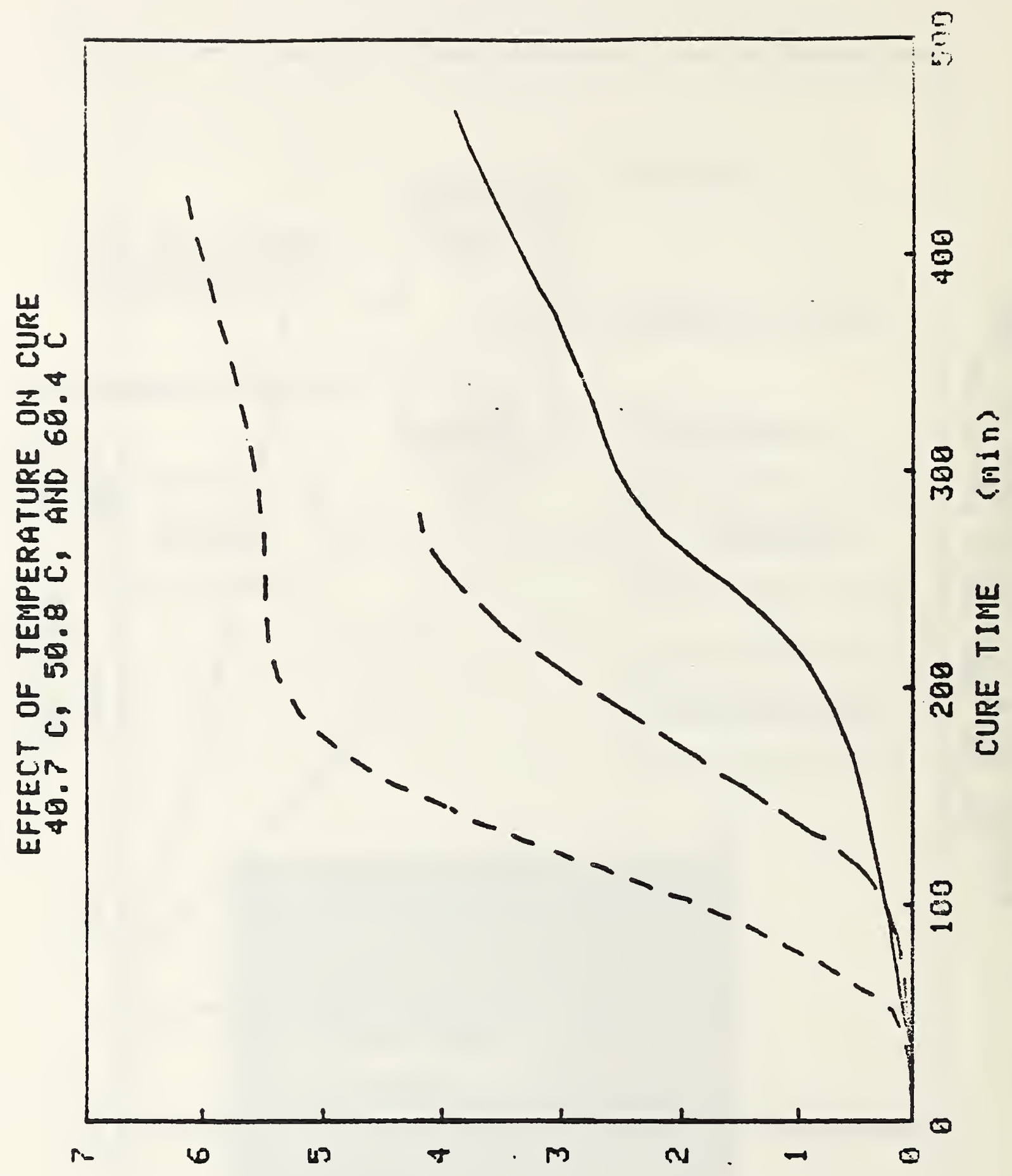


Figure 5

\section{POKER-CHIP TEST}
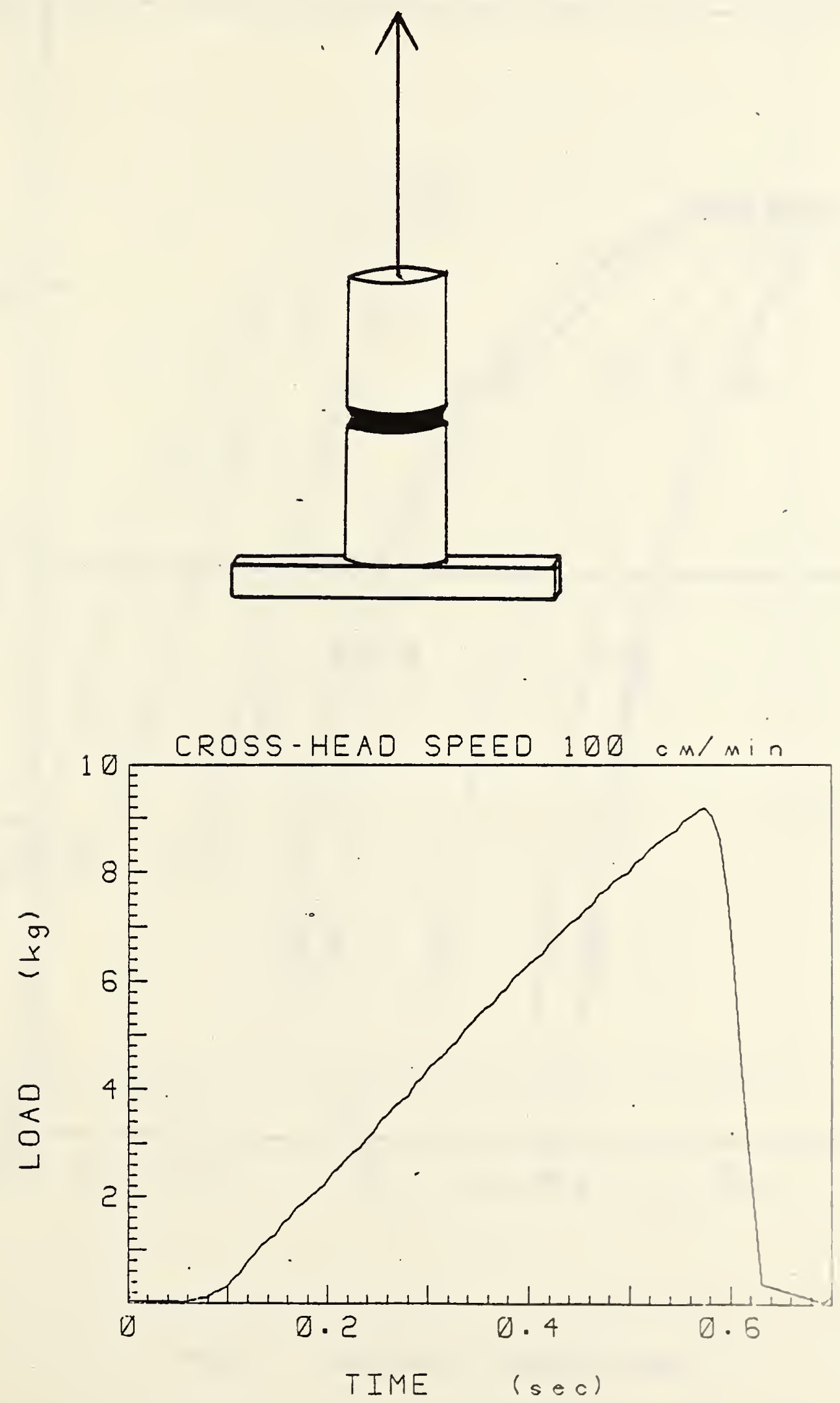


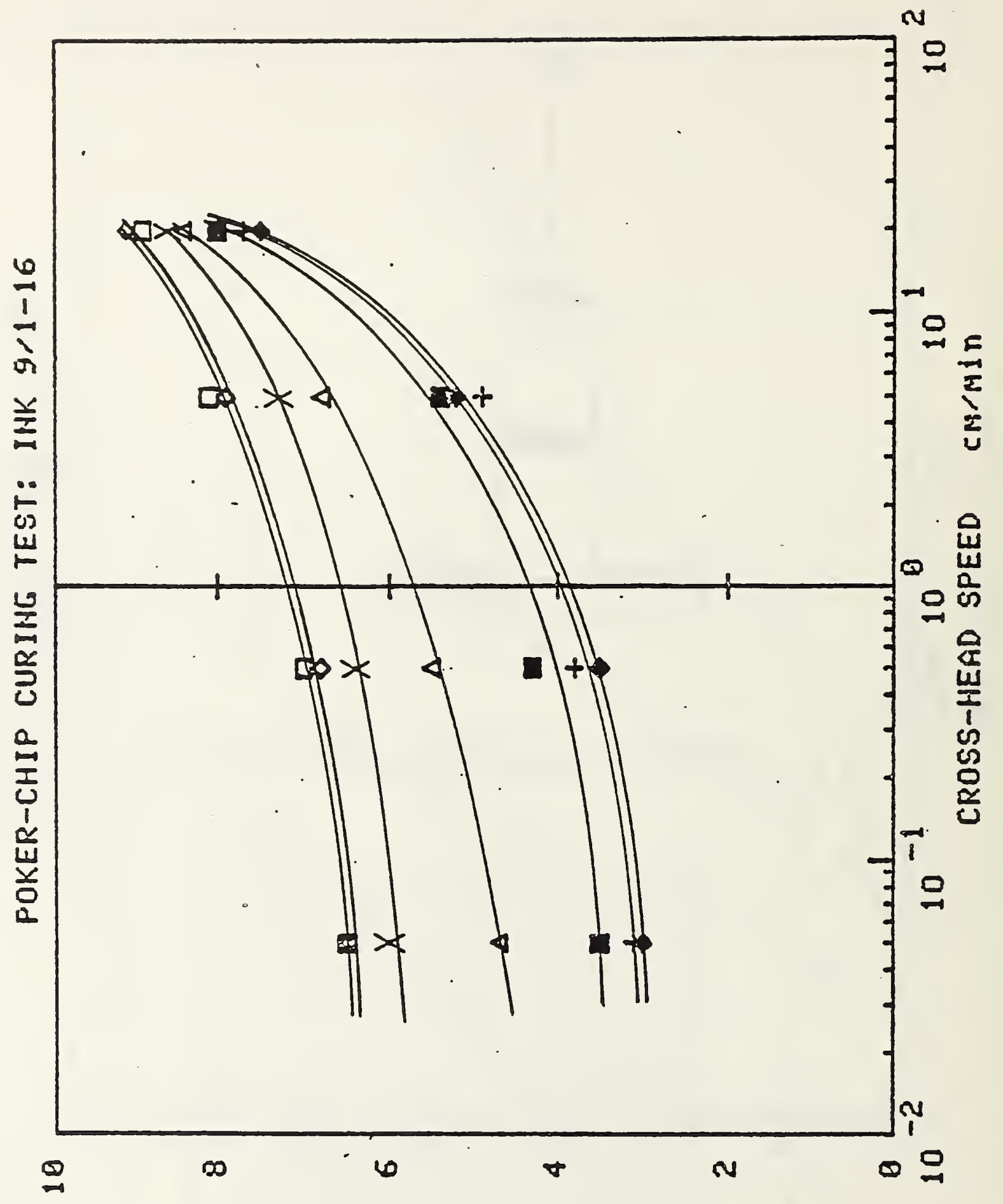




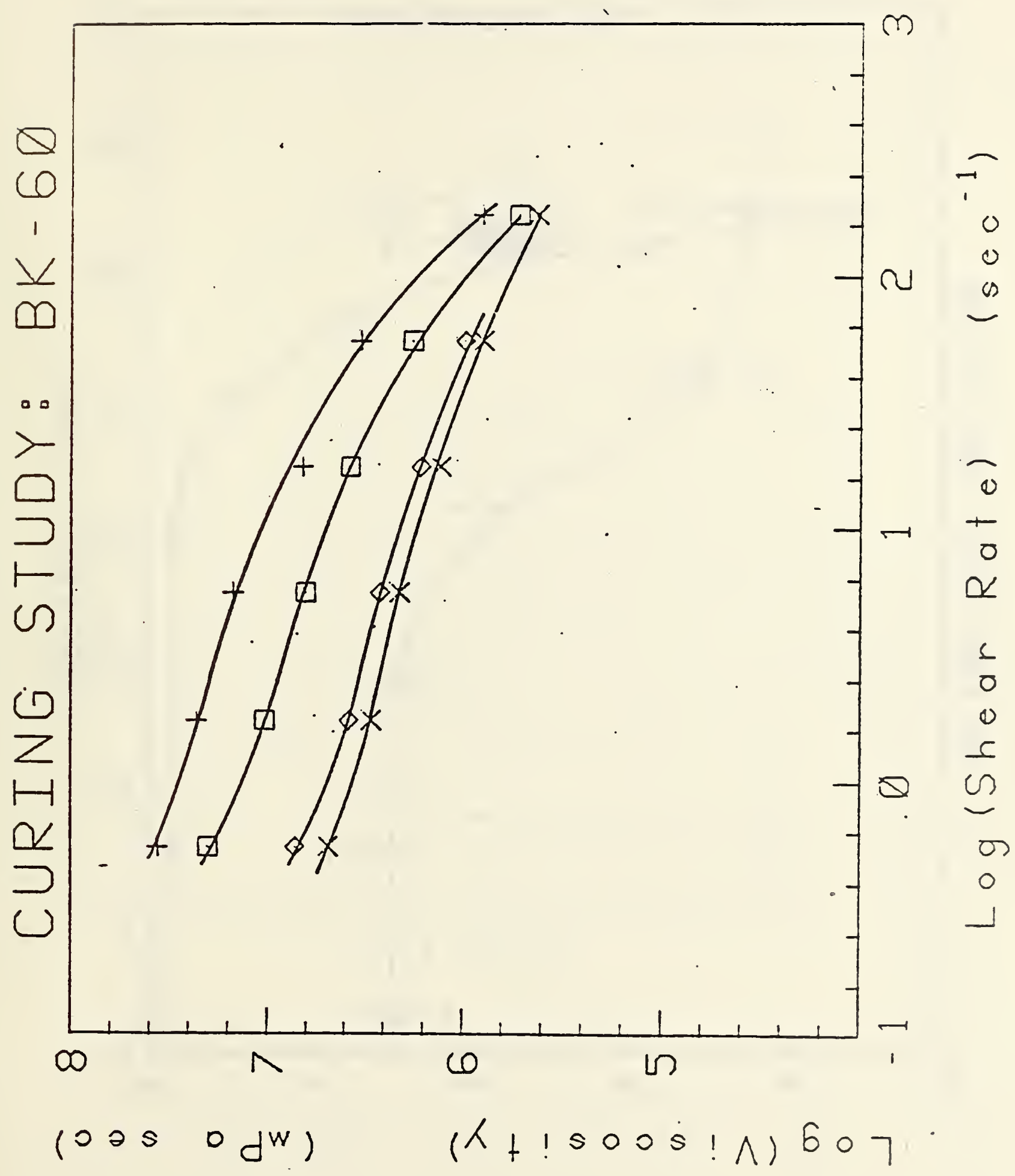


Figure 8

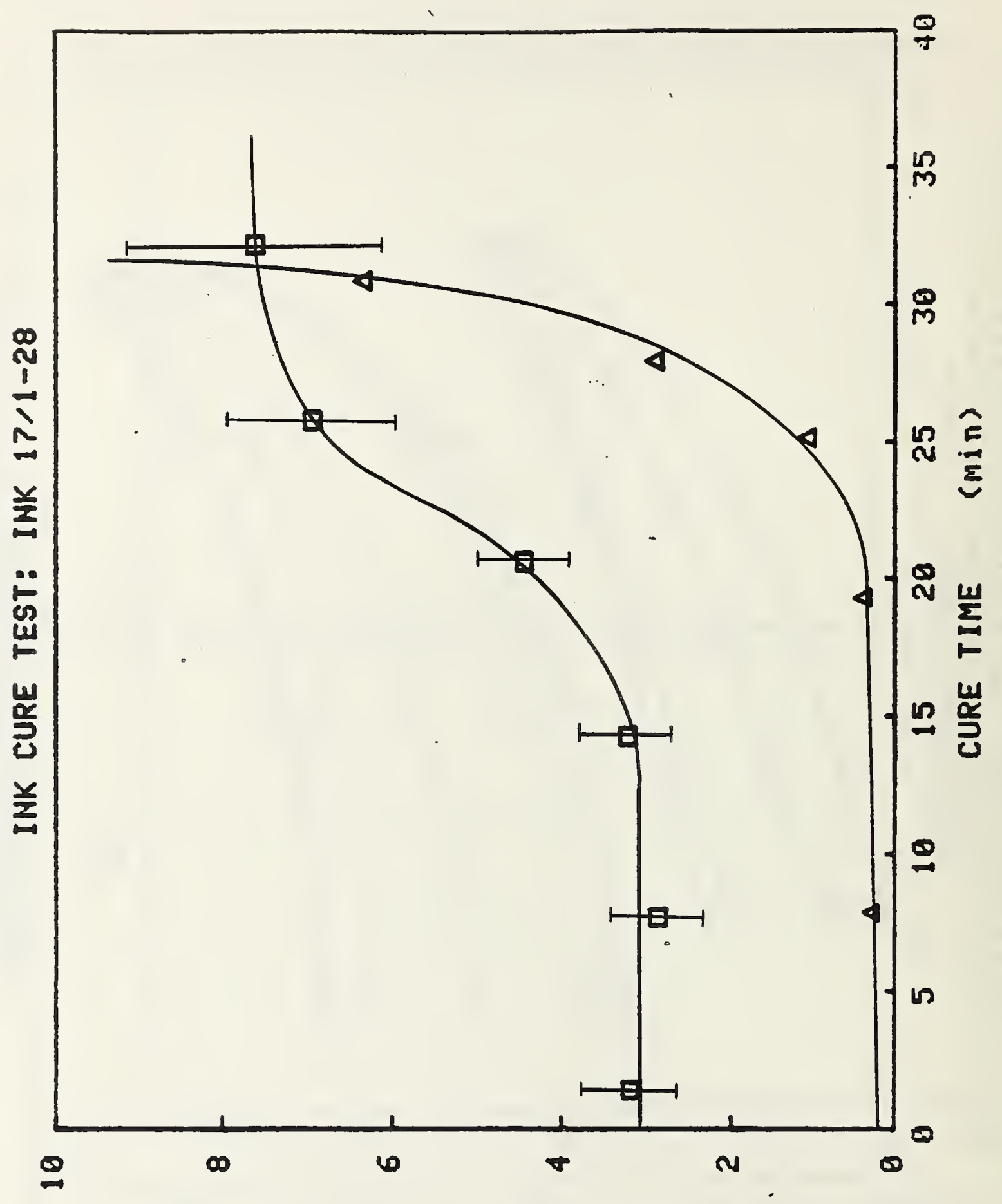


Figure 9

SQUEEZE FLOW TEST
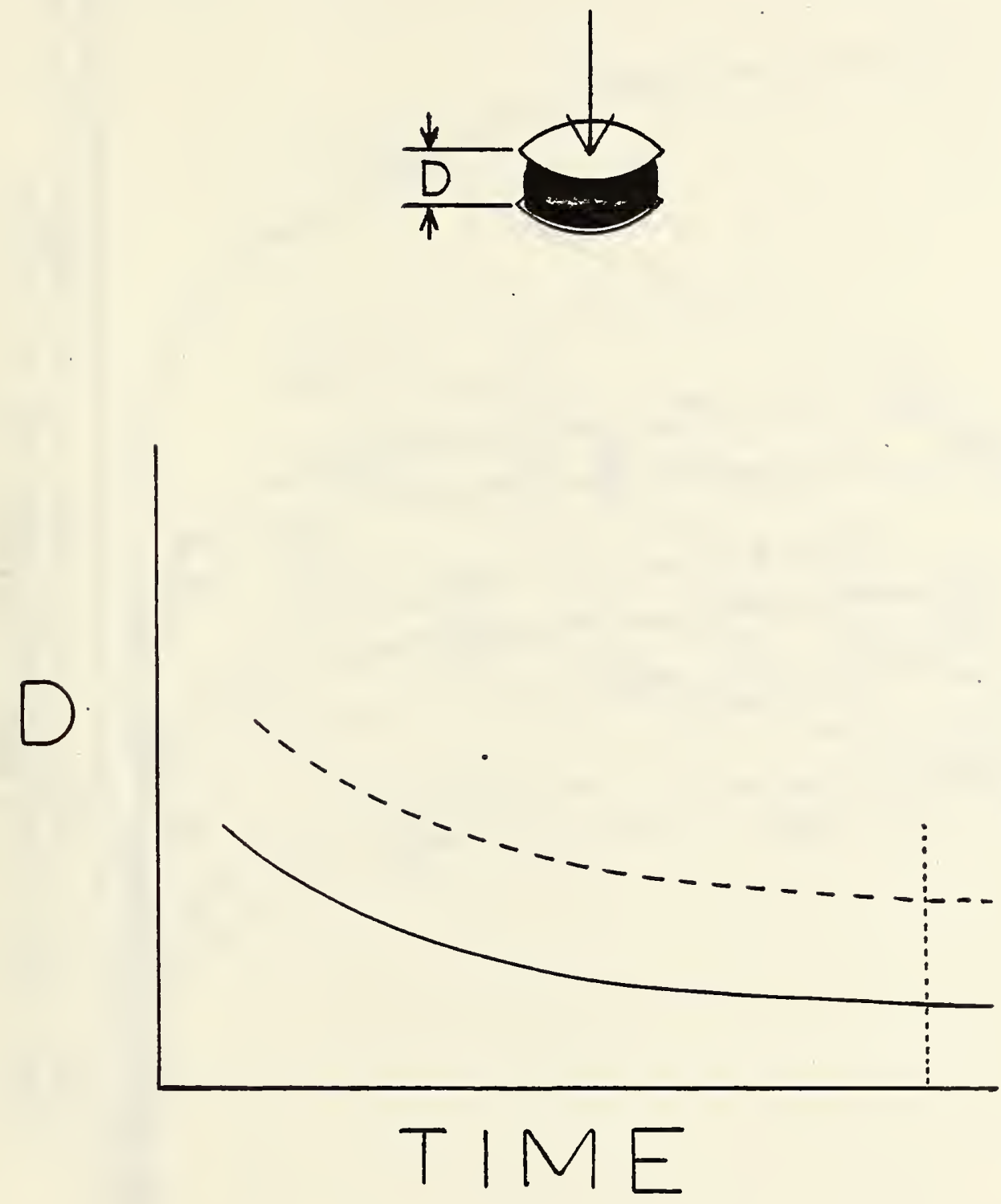


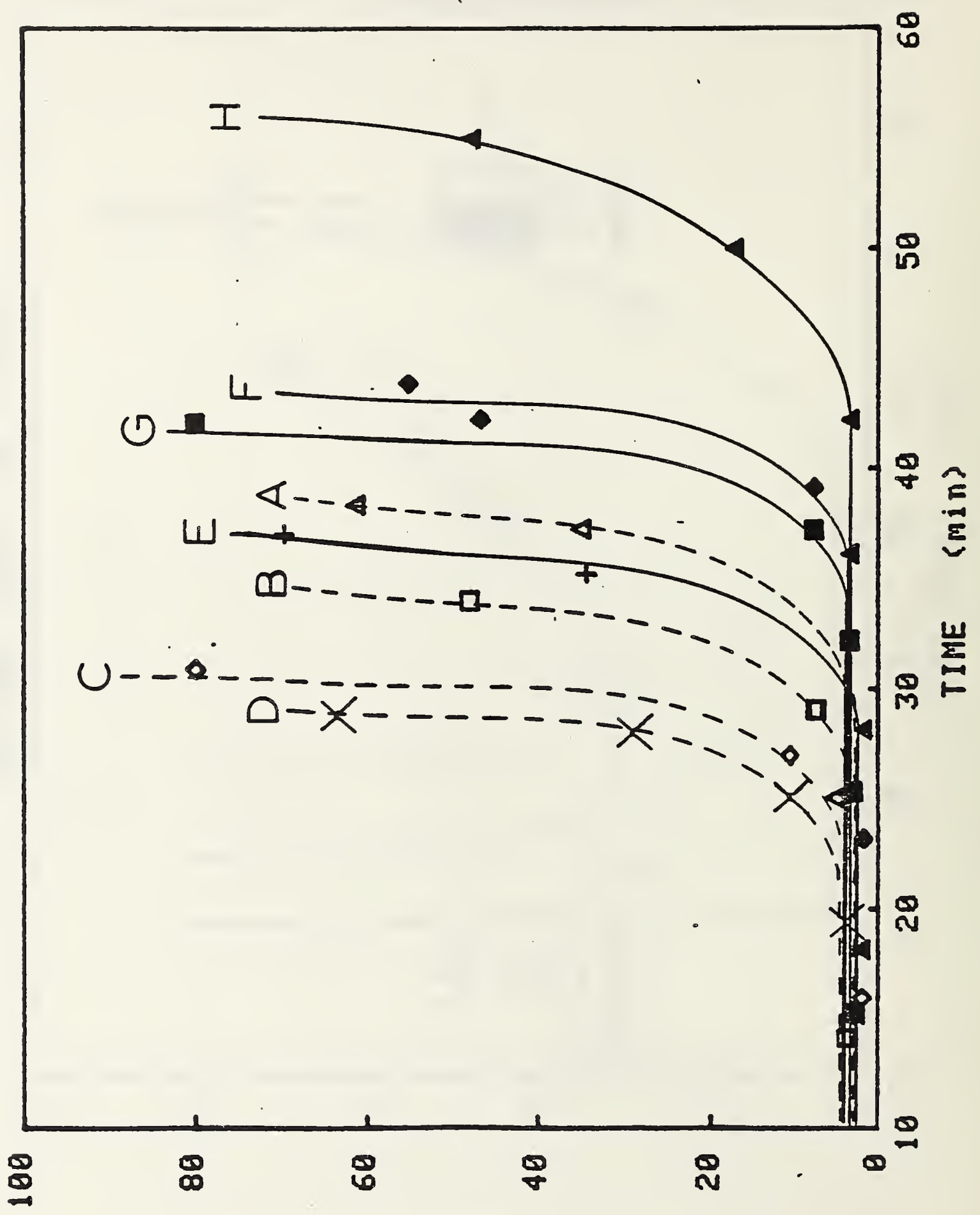




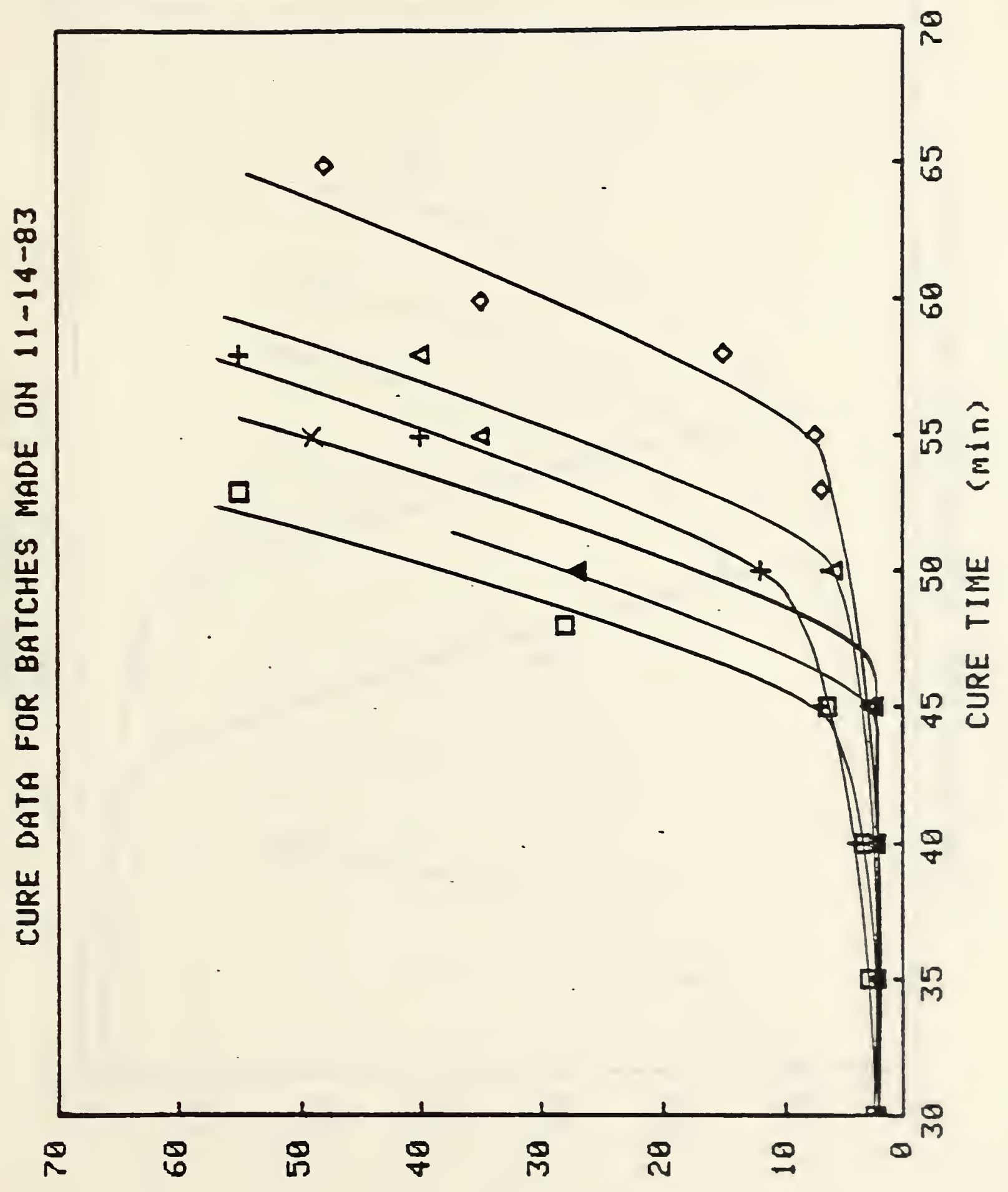




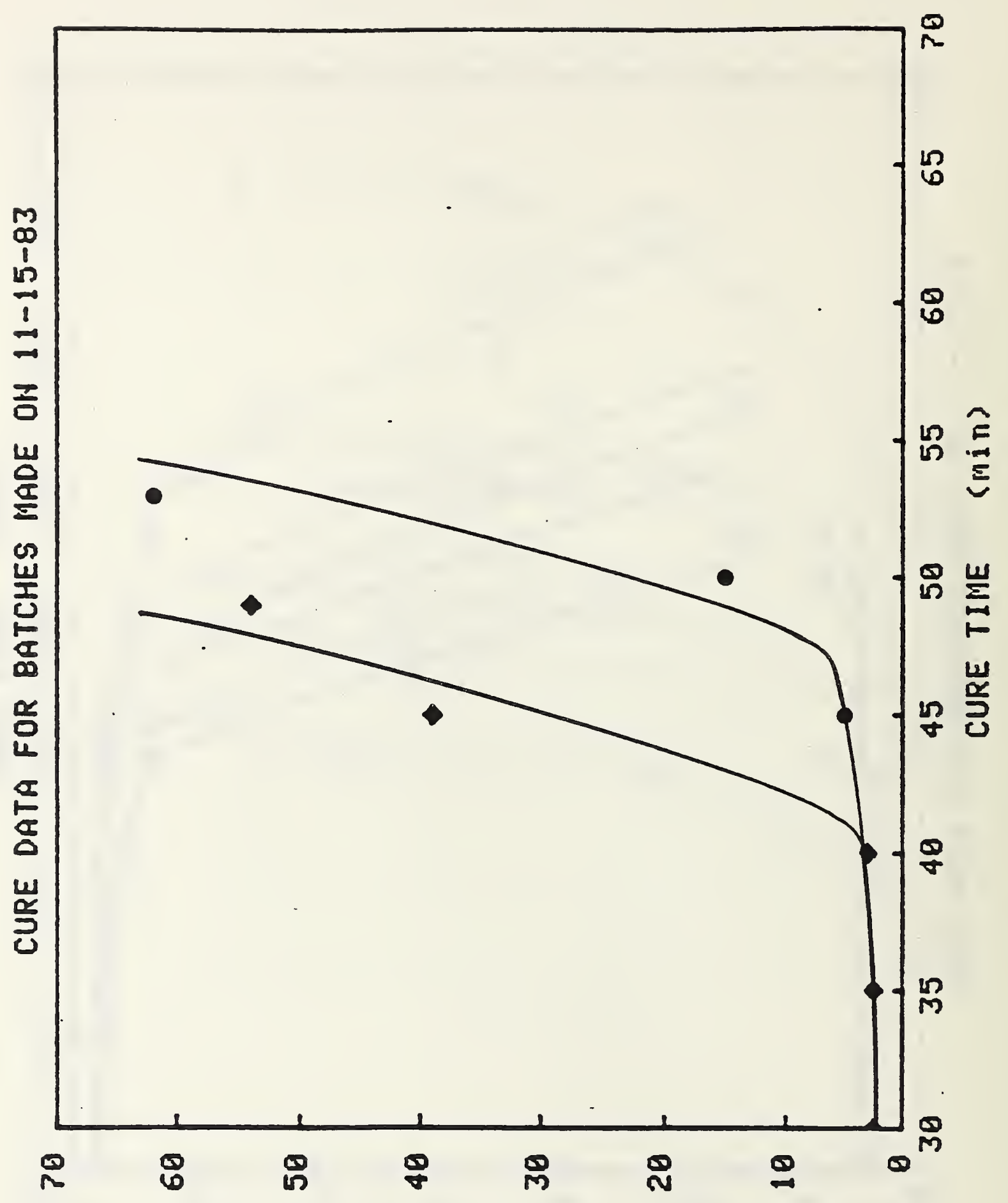


Figure 13

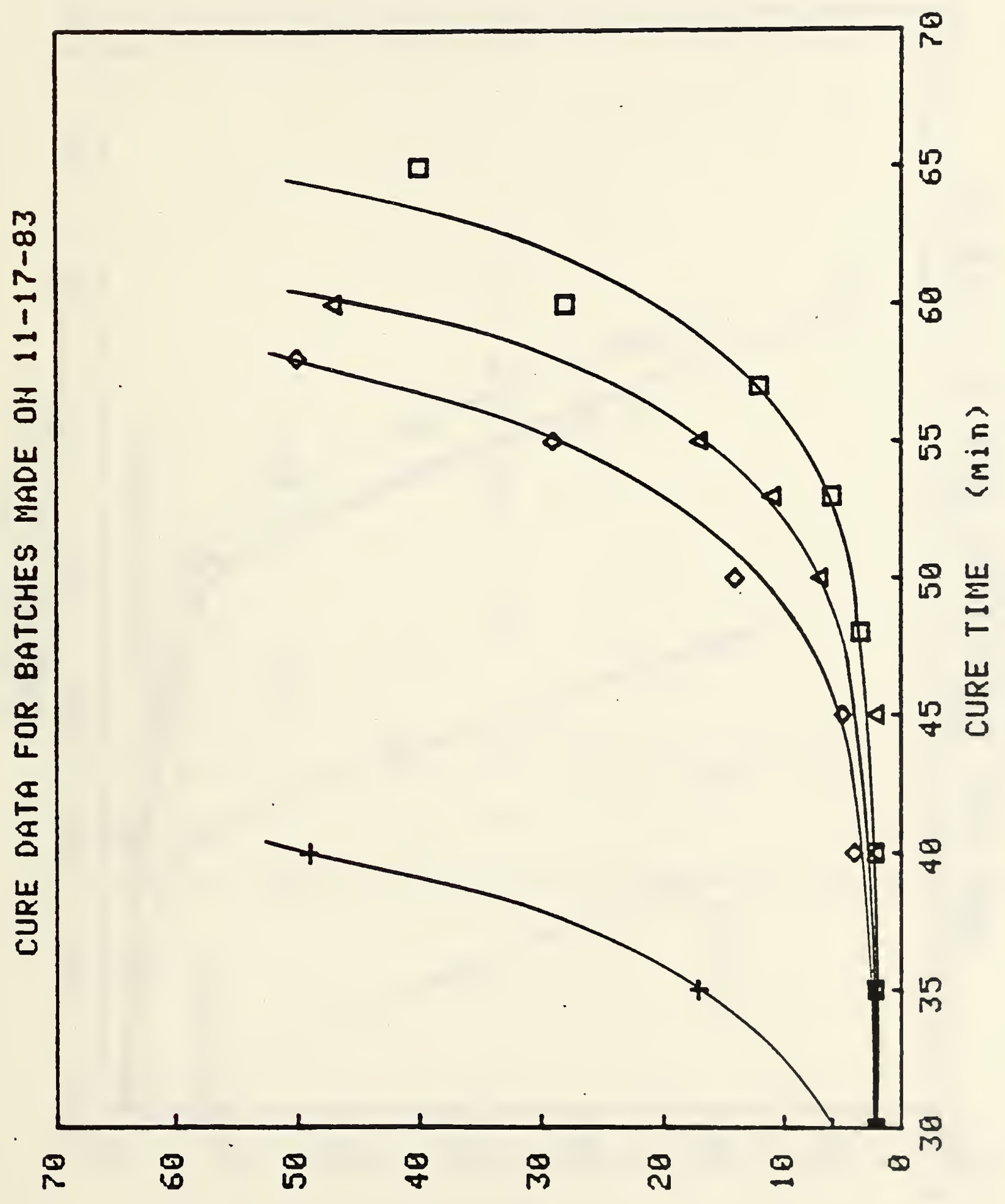




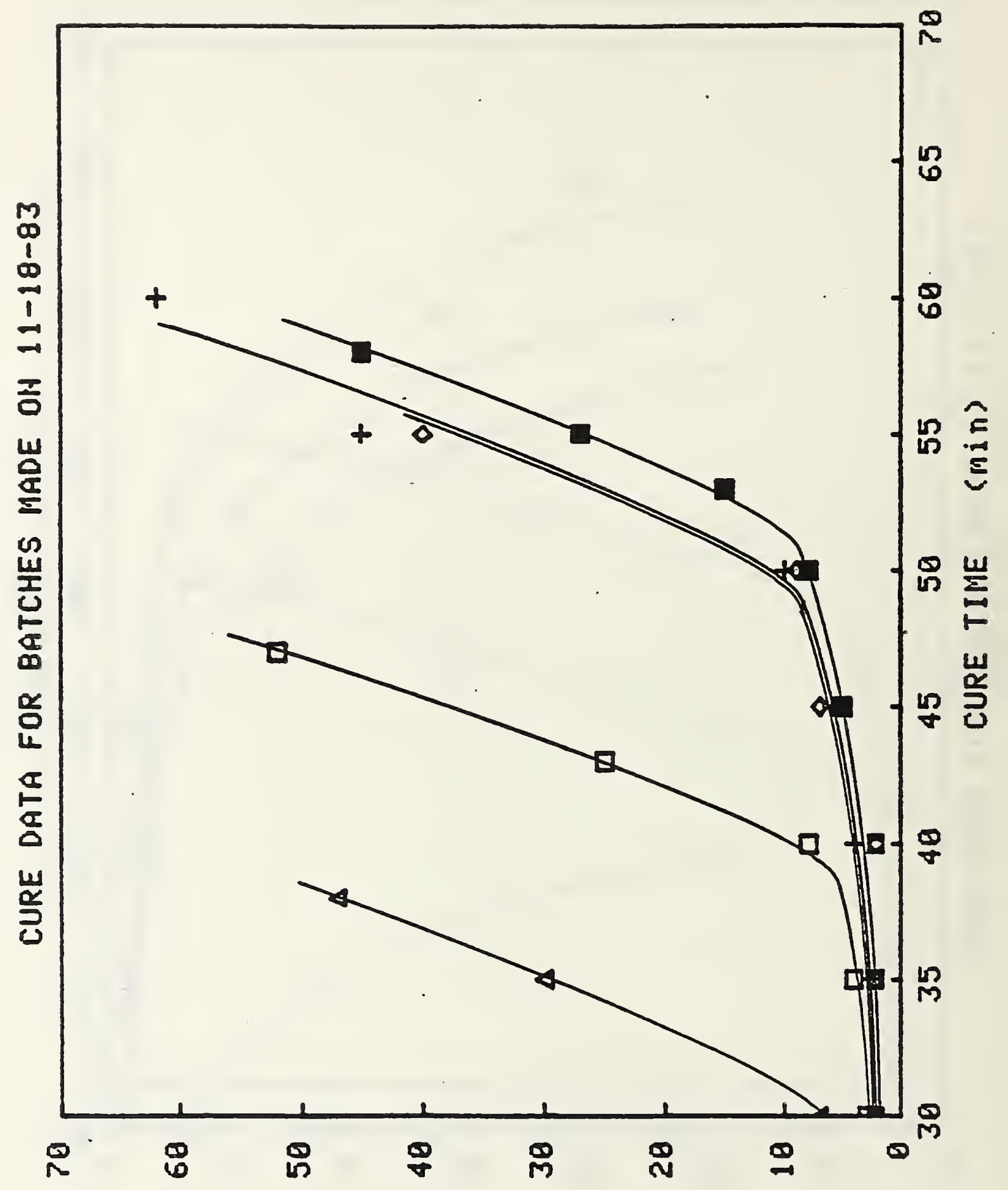


Figure 15

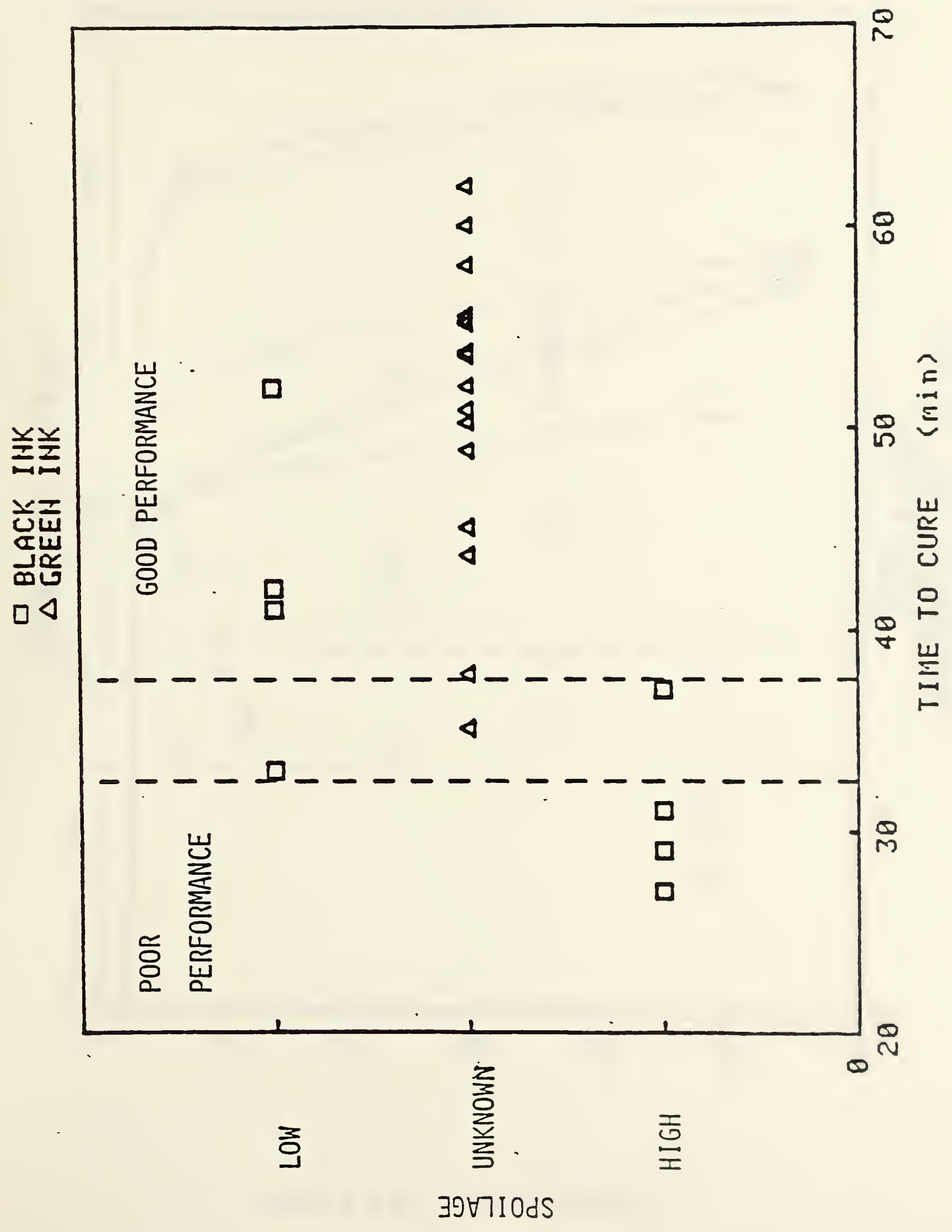




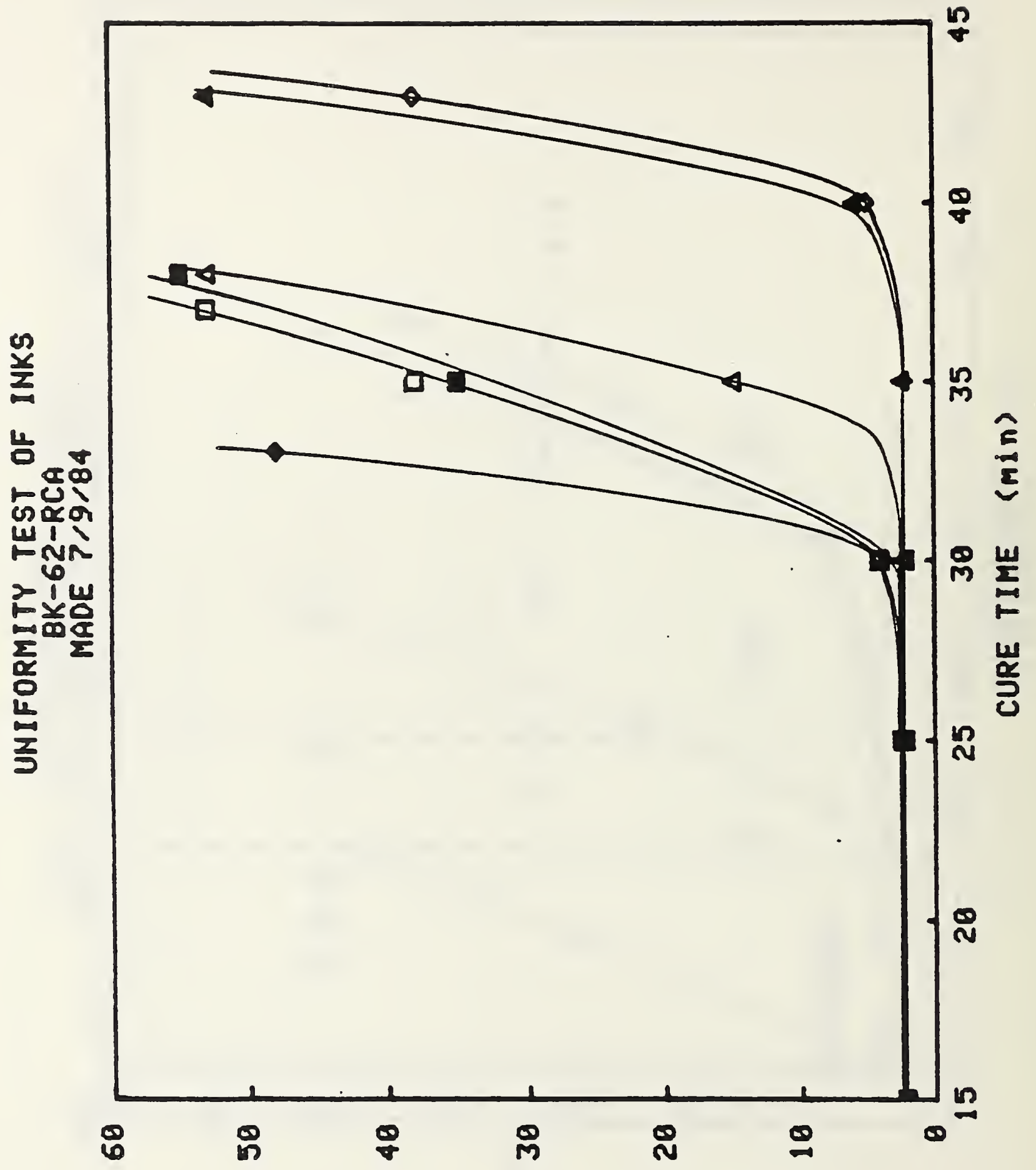


Figure 17

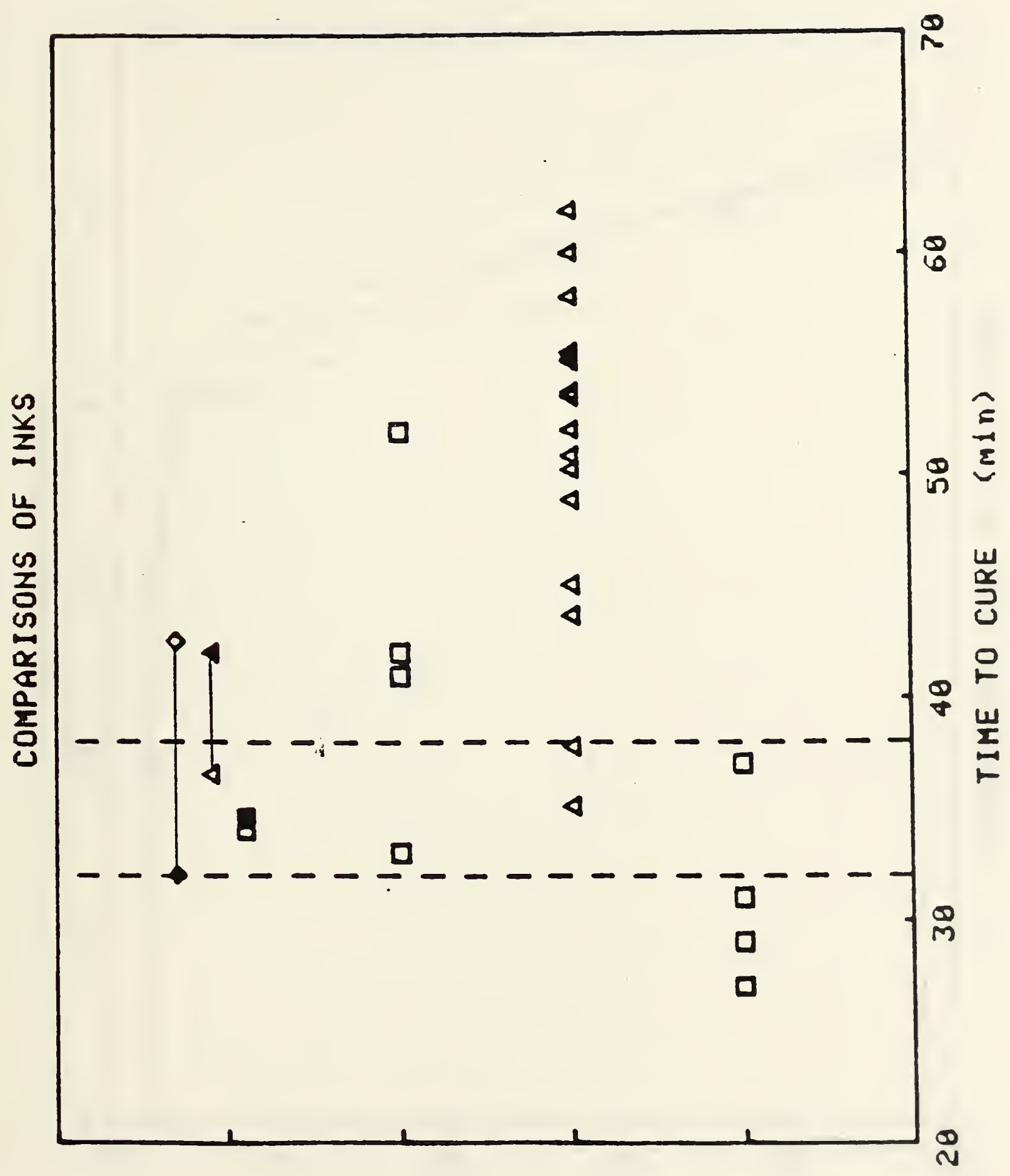




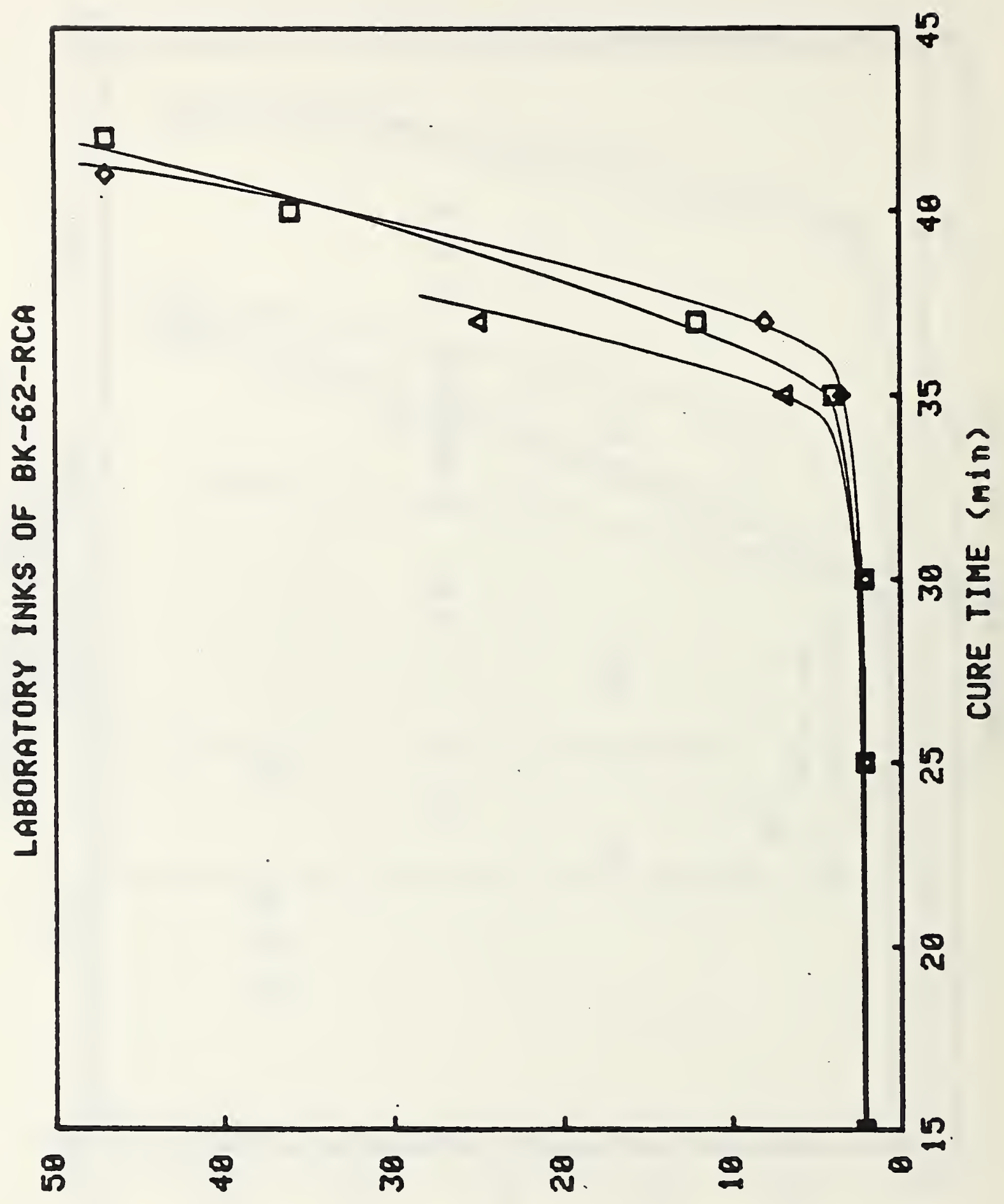




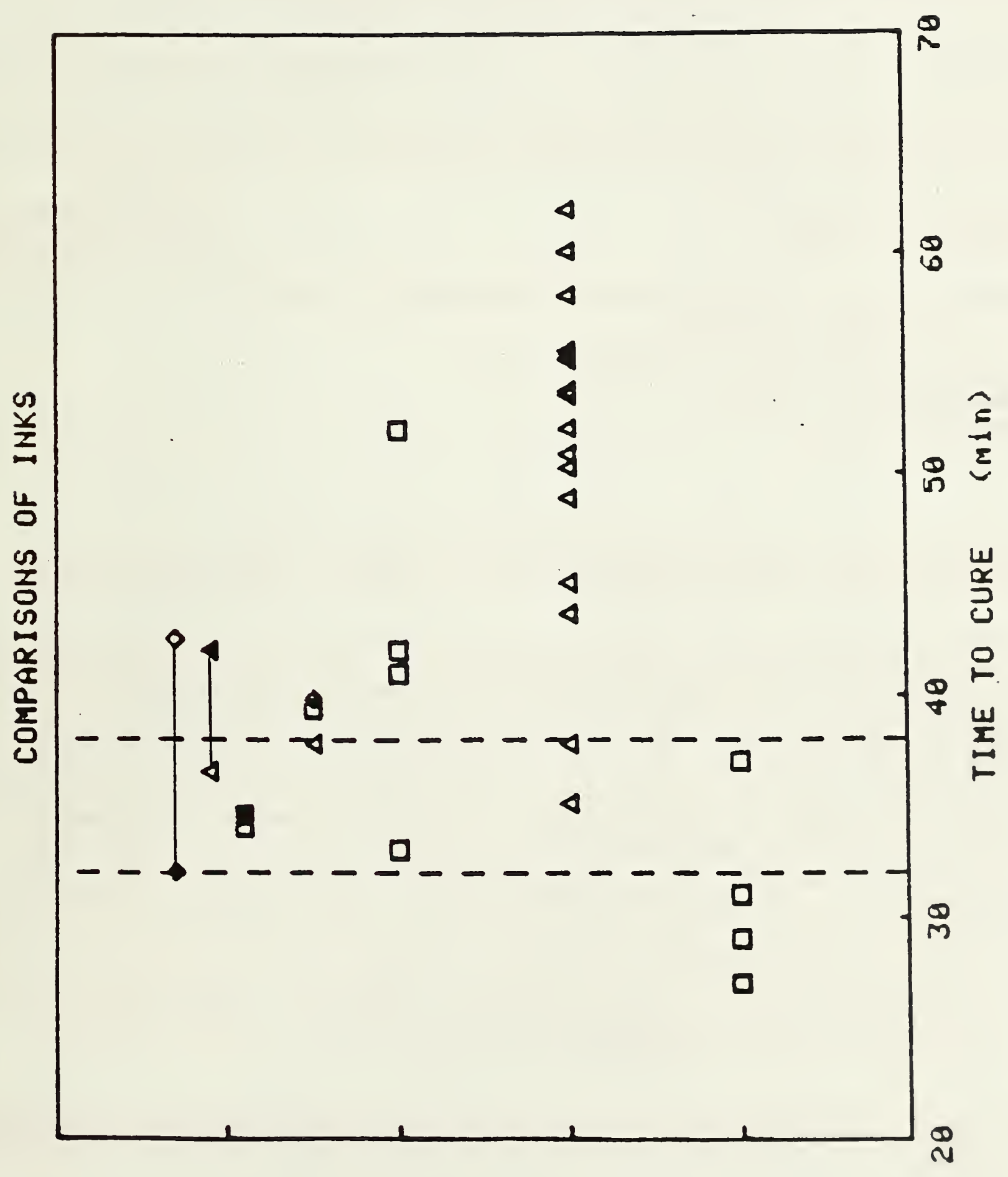


BIBLIOGRAPHIC DATA

SHEET (See in structions)

4. TITLE AND SUBTITLE

Relationships Between Mechanical Properties and Performance of Inks

as the Basis for Quality Control Techniques: Part III

5. $A \cup T H O R(S)$

Donald L. Hunston and George W. Bullman

6. PERFORMING ORGANIZATION (If joint or other than NBS, see instructions)

NATIONAL BUREAU OF STANDARDS

DEPARTMENT OF COMMERCE

WASHINGTON, D.C. 20234

7. Contract Grant No. $W-0840-00$

8. Type of Report \& Period Covered Annual Report 1984

9. SPONSORING ORGANIZATION NAME AND COMPLETE ADDRESS (Street, City, Stote. ZIP)

U.S. Department of Treasury

Bureau of Engraving and Printing

Department of Research and Technical Service

Washington, D.C. 20226

10. SUPPLEMENTARY NOTES

Document describes a computer program; SF-185, FIPS Software Summary, is attached.

11. ABSTRACT (A 200-word or less foctual summary of most significant information. If document includes a signifleant bibliogrophy or literoture survey. mention it here)

This report reviews the progress of a joint program with the Bureau of Engraving and Printing (BEP) designed to study the mechanical properties of ink both before and during curing. The objectives are to develop quality control tests and guidelines for improved ink formulations. This report covers progress in a number of specific research areas. First, the development of a variety of test methods is discussed. These methods include shear viscosity measurements, squeeze flow experiments, and the poker-chip test. Second, the correlation that was developed previously between ink drying behavior and press performance is examined further. Large batch-to-batch variations in drying behavior were found for production inks, and this is concluded to be a major contributor to poor ink performance since the press can not be adjusted to compensate for these rapid and unpredictable variations. Thire, the variations in properties within an ink batch were studied and found to be a significant fraction of the between batch variations. Finally, Laboratory inks were prepared and studied. These inks exhibited relatively little variation either within or between batches. Consequently, the results indicate that model inks can be prepared in the Laboratory for systematic studies of property-performance relationships.

12. KEY WORDS (Six to twelve entries; alphabetical order; capitalize only proper names; and separate key words by semicolons) curing; drying; intaglio ink; printing; quality control; rheology; viscoelasticity; viscosity

13. AVAILABILITY

\section{Xunlimited}

For Official Distribution. Do Not Release to NTIS

Order From Superintendent of Documents, U.S. Government Printing Office, Washington, D.C. 20402.
14. NO. OF

PRINTED PAGES

48

15. Price

$\$ 9.95$ 


\section{-}

- 
